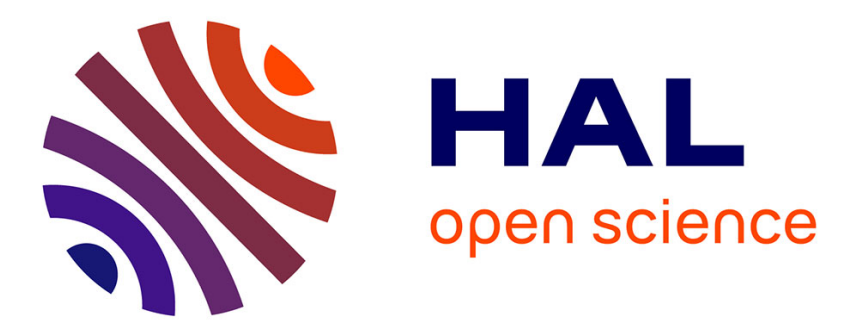

\title{
Mycotoxic nephropathy in Bulgarian pigs and chickens: complex etiology and similarity to Balkan Endemic Nephropathy
}

Stoycho Stoev, Michael Dutton, Patrick Njobeh, Joseph Mosonik, Paul Steenkamp

\section{To cite this version:}

Stoycho Stoev, Michael Dutton, Patrick Njobeh, Joseph Mosonik, Paul Steenkamp. Mycotoxic nephropathy in Bulgarian pigs and chickens: complex etiology and similarity to Balkan Endemic Nephropathy. Food Additives and Contaminants, 2009, 27 (01), pp.72-88. 10.1080/02652030903207227. hal-00573918

\section{HAL Id: hal-00573918 https://hal.science/hal-00573918}

Submitted on 5 Mar 2011

HAL is a multi-disciplinary open access archive for the deposit and dissemination of scientific research documents, whether they are published or not. The documents may come from teaching and research institutions in France or abroad, or from public or private research centers.
L'archive ouverte pluridisciplinaire HAL, est destinée au dépôt et à la diffusion de documents scientifiques de niveau recherche, publiés ou non, émanant des établissements d'enseignement et de recherche français ou étrangers, des laboratoires publics ou privés. 


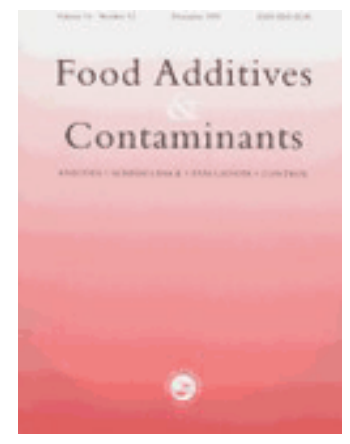

\section{Mycotoxic nephropathy in Bulgarian pigs and chickens: complex etiology and similarity to Balkan Endemic Nephropathy}

\begin{tabular}{|r|l|}
\hline Journal: & Food Additives and Contaminants \\
\hline Manuscript ID: & TFAC-2009-100.R1 \\
\hline Manuscript Type: & Original Research Paper \\
\hline Author: & 28-Jun-2009 \\
\hline & $\begin{array}{l}\text { Complete List of Authors: } \\
\text { Nubmitted by the } \\
\text { and Health Research Groutrick; University of Johannesburg, Food, Environment } \\
\text { and Health Research Group, Faculty of Health Science } \\
\text { Mosonik, Joseph; University of Johannesburg, Food, Environment } \\
\text { and Health Research Group, Faculty of Health Science } \\
\text { Steenkamp, Paul; Council for Scientific and Industrial Research, } \\
\text { Biosciences }\end{array}$ \\
\hline Methods/Techniques: & HPLC, Mycology, Screening assays, Toxicology - animal study \\
\hline Additives/Contaminants: & $\begin{array}{l}\text { Fumonisins, Mycotoxins, Mycotoxins - fungi, Mycotoxins - } \\
\text { ochratoxin A }\end{array}$ \\
\hline Food Types: & Animal feed \\
\hline & \\
\hline
\end{tabular}

\section{SCHOLARONE \\ Manuscripts}




\title{
Mycotoxic nephropathy in Bulgarian pigs and chickens: complex etiology and similarity to Balkan Endemic Nephropathy
}

\author{
Stoycho D. Stoev ${ }^{a^{*}}$ Michael F. Dutton $^{\mathrm{b}}$, Patrick B. Njobeh ${ }^{\mathrm{b}}$, Joseph S. Mosonik ${ }^{\mathrm{b}}$, Paul A. \\ Steenkamp ${ }^{c}$
}

${ }^{a}$ Department of General and clinical pathology, Faculty of Veterinary Medicine, Trakia University, Students campus, 6000 Stara Zagora, Bulgaria

${ }^{b}$ Food, Environment and Health Research Group, Faculty of Health Science, University of Johannesburg, Doornfontein 2028, Gauteng, PO Box 17011, South Africa

${ }^{c}$ Council for Scientific and Industrial Research, Biosciences, Ardeer Road, Private Bag x2, Modderfontein, 1645, South Africa

\section{Running Title: Complex etiology of Bulgarian nephropathy}

Key words: ochratoxin A, penicillic acid, citrinin, fumonisin B1, mycotoxins, mycotoxic nephropathy

\begin{abstract}
Abbreviations: AFs - aflatoxins, BEN - balkan endemic nephropathy, CIT - citrinin, CA cyclopiazonic acid, DAS - diacetoxyscirpenol, DON - deoxynivalenol, ERY - erythroskyrin, FB1 - fumonisin B1, FB2 - fumonisin B2, GLI - gliotoxin, ISL - islandiotoxin, KA - kojic acid, LUT - luteoskyirin, MPN - mycotoxic porcine nephropathy, MCN - mycotoxic chicken nephropathy, MON - moniliformin, UM - unknown metabolite, OTA - ochratoxin A, OTC ochratoxin C, OOS - oosporein (isoosporin), PenA - penitrem A, PAT - patulin, PA penicillic acid, RUB - rubratoxin $\mathrm{B}, \mathrm{T}-2$ - T-2 toxin, XA - xanthomegnin, ZEA zearalenone.
\end{abstract}

\footnotetext{
* Corresponding author: S. D. Stoev, Department of General and Clinical Pathology, Faculty of Veterinary Medicine, Trakia University, Students campus, 6000 Stara Zagora, Bulgaria, Tel: +35942 670540; E-mail: stoev@uni-sz.bg
} 


\begin{abstract}
Spontaneous nephropathy in Bulgaria, which is observed frequently during the meat inspection and which differs morphologically from the classical description of mycotoxic porcine/chicken nephropathy as made in Denmark, was found to have multi-mycotoxic etiology being mainly provoked by combined effect of ochratoxin A, penicillic acid and fumonisin B1 in addition to a not yet known metabolite. Mean contamination levels of ochratoxin A were consecutively low (188.8 and $376.4 \mu \mathrm{g} / \mathrm{kg})$ in contrast to high contamination levels of fumonisin B1 (5564.1 and $3254.5 \mu \mathrm{g} / \mathrm{kg}$ ) and penicillic acid (838.6 and $904.9 \mu \mathrm{g} / \mathrm{kg}$ ) for years 2006 and 2007 respectively. Some other mycotoxins with lower importance such as citrinin, penitrem A, etc, may also influence clinicopathological picture of this nephropathy. A heavy contamination with Gibberella fujikuroi var. moniliformis (Fusarium verticillioides) and Penicillium aurantiogriseum complex (mainly Penicillium polonicum) was observed in almost all examined feed samples coming from pig- and chick farms with nephropathy problems from Bulgaria. In contrast, low contamination with Aspergillus ochraceus, Penicillium verrucosum and Penicillium citrinum was observed in the same feed samples and these species were isolated as very rare components of the mycobiota.
\end{abstract}




\section{INTRODUCTION}

It is known that mycotoxic nephropathy $(\mathrm{MN})$ is a renal disease caused by alimentary ingestion of secondary fungal metabolites with nephrotoxic properties, which can be found in feeds and foods made mainly from cereals or fibrous plants, and kept in storehouse conditions and increased humidity. The disease has various names: nephrosis provoked by moulds, chronic interstitial fibrosis of kidneys, chronic interstitial nephritis, etc. However, the terms "ochratoxicosis" and "mycotoxic nephropathy" are the most frequently used for describing this nephropathy. It is important to mention that there are some variances with the clinicomorphological picture of that disease, which in many cases is provoking by combined nephrotoxic effect of several mycotoxins (Stoev et al., 1998a, 2001, 2002a; Stoev, 2008b) and is additionally influenced by some secondary bacterial infections as a result of the significant immunosuppression in the affected animals (Stoev et al., 2000a,b; Oswald et al., 2003, 2005).

Ochratoxin A (OTA), citrinin (CIT) and fumonisin B1 (FB1) are reported to be nephrotoxic mycotoxins and probably are involved in some cases of nephropathy in various countries (Voss et al., 2001; Stoev, 2008a,b; Stoev et al., 1998a,b). Fumonisins are mycotoxins produced by Fusarium verticillioides ( $F$. moniliforme), Fusarium proliferatum and related Fusarium species found mainly in corn (maize) (Dutton and Kinsey, 1995), whereas OTA is mainly produced by $A$. ochraceus and $P$. viridicatum, which are storage fungi and often contaminate various animal and human feeds/foods stored for a long period of time. Penicillic acid (PA) can be produced by $P$. aurantiogriseum strains and the same ochratoxinogenic fungi from the Aspergillus ochraceus group, which are the major producers of OTA in the warmer climatic zones (Stoev et al., 1998a; Stoev, 2008a). CIT is produced mainly by Penicillium citrinum, which is also a storage fungus. However, only scarce data are available about a combined exposure to OTA, CIT, FB1 and PA, which might spontaneously occur under field conditions (Stoev et al., 2002a; Stoev, 2008b). In this context, some mycological investigations of animal feeds, suspicious to cause porcine nephropathy in Bulgaria, revealed the presence of a P. aurantiogriseum strains (Stoev et al., 1998a), which are potent producers of PA.

The established concentrations of OTA in Bulgarian feeds from farms with nephropathies (100-200 $\mu \mathrm{g} / \mathrm{kg}$ ) were at least 5-fold less than that presented as the explanation for Danish mycotoxic porcine (MPN) or chicken (MCN) nephropathy (Stoev et al., 1998a,b, 2002a). Therefore, it can be concluded that the animals' intake of OTA is much lower than that shown to be necessary (Krogh, 1976), even for less severe symptomatology, as can be seen from all experimental studies with OTA. It is obvious, that Bulgarian porcine/chicken nephropathy may have a multitoxic aetiology because it cannot be explained by the 
concentration of OTA alone (Stoev et al., 1998a, 2002a). The low feed- and serum levels of OTA in MPN-affected farms are also very similar and comparable to those found in food and blood of humans with Balkan Endemic Nephropathy (BEN), widely ranged in Bulgaria and other Balkan countries (Petkova-Bocharova et al., 1991; Petkova-Bocharova and Castegnaro, 1991; Stoev and Petkova-Bocharova, 1994). These very similar toxicological findings strongly suggest a possible common aetiology in both diseases - BEN and MPN (Stoev, 1998).

It is also expected that mixtures of mycotoxins would have at least an additive, if not synergistic toxic effect. The presence of multiple mycotoxins in various feeds presents new concerns since toxicological information on the effects of simultaneous exposure is still very limited. Although, the prediction of the effect of multiple toxins is difficult, certain in vitro or in vivo studies can help us predict the outcome (Klaric et al., 2007; Kubena et al., 1997; Stoev et al., 2001, 2004; Stoev, 2008a,b). On the other hand, we have induced porcine- as well as chicken nephropathies using a mouldy diet containing very low levels of OTA (180-300 $\mu \mathrm{g} / \mathrm{kg}$ ) in combination with PA (Stoev, 2000; Stoev et al., 1999, 2000a, 2001, 2004). The more potent toxicity of OTA in these studies might be due to synergistic toxic effects when OTA is simultaneously administered with PA, as has been reported in mice (Sansing et al., 1976; Shepherd et al., 1981) and in poultry (Micco et al., 1991). The OTA-producers used in the mentioned above experiments produced both toxins (OTA and PA) simultaneously. In this context, some authors have suggested about the important role of the pancreatic enzyme carboxypeptidase A in the partial detoxification of OTA in the small intestine in rats (Doster and Sinhuber, 1972; Suzuki et al., 1977). It was found by Parker and collaborators (1982) that PA inhibits carboxypeptidase activity both "in vitro" and "in vivo", and such inhibition may significantly impair the partial detoxification of OTA in the intestinal tract and so be partly responsible for the enhanced toxicity of OTA, when the same mycotoxin is ingested together with PA. Moreover, the hepatobiliary excretory dysfunction, which can be provoked by PA (Chan and Hayes, 1981) may also result in decreasing of hepatobiliary excretion of OTA. Recently, an opinion was expressed, that such synergism between OTA and other mycotoxins (as PA, CIT or FB1) under field conditions may be responsible for the spontaneous MPN (Stoev et al., 1998a,b) and MCN (Stoev et al., 2002a) in Bulgaria, which can be caused by relatively low contamination levels of OTA in feed $(207.10 \pm 65.14 \mu \mathrm{g} / \mathrm{kg}$ in $1993,114.06 \pm$ $35.79 \mu \mathrm{g} / \mathrm{kg}$ in 1994 and $196.2 \pm 45.9 \mu \mathrm{g} / \mathrm{kg}$ in 1997). In addition, the more distinctive features of spontaneous MPN (e.g. enlargement of renal lymph nodes, neoplastic changes, significantly enlarged and marbled or pale appearance of kidneys as well as cystic or stronger fibrotic changes in cortex of the kidneys) and $\mathrm{MCN}$ (e.g. nervous symptoms, vascular and 
oedematous changes in various internal organs and the brain, and subcutaneous or liver and kidney haemorrhages in addition to known degenerative changes in the kidneys, liver and lymphoid organs) in Bulgaria may result largely from the effects of nephrotoxic metabolites other than OTA (Stoev et al., 1998a, 2002a) or may be attributed to synergistic effects between OTA and other mycotoxins, and the increase of OTA-toxicity (Stoev, 2008b). These features were not observed in nephropathy provoked by pure OTA, given at doses and for periods of exposure similar to those in the field (Krogh et al., 1974; Elling et al., 1985; Stoev et al., 2002b) or associated with Danish MPN (Krogh, 1976; Elling, 1977). The low contamination levels of OTA in fed forages as well as the high incidence of MPN (Stoev et al., 1998a) and MCN (Stoev et al., 2002a) in Bulgaria suppose a possible synergistic interaction between OTA and other mycotoxins (produced by the same ochratoxinogenic- or other fungi) enhancing the nephrotoxicity of OTA and/or having additional nephrotoxic effect, which needs to be proved.

Therefore, the objective of this study is to carry out more field toxicological investigations in order to assess the involvement probability of all possible mycotoxins (especially nephrotoxic mycotoxins as OTA, CIT and FB1 as well as mycotoxins having synergistic effects on their action as PA, etc) in etiology of MPN and MCN, encountered largely in some regions in Bulgaria. On the other hand, the risk assessment for animals and humans potentially exposed to multi-mycotoxins suffers from the lack of adequate information, because synergistic or antagonistic interaction between various mycotoxins are often present, but not taken into account.

\section{MATERIALS AND METHODS}

\section{Sampling}

Twenty-five feed samples were taken in years 2006 and 2007 (a total 50 feed samples) from various pig/chick farms in Bulgaria having nephropathy problems (enlarged and mottled or pale appearance of kidneys) at slaughter time (Figure 1). Some of the samples came from affected farms and may represent the actual toxic feed. Other samples came directly from commercial feed plants or from long-term stores, which were the main source of the feeds in the same farms and would not be directly representative of the nephrotoxic feed, because sampling was always retrospective. The content of various ingredients as wheat or barley in these commercial feed samples was often different, but the maize content was usually high. The feed samples were then frozen at $-20^{\circ} \mathrm{C}$ until analysis.

Blood and urine samples were also collected in years 2006 and 2007 (a total 20 blood and 20 urine samples). All blood or urine samples were taken at slaughter time from 40 
different pigs having nephropathy problems and originating from 4 of the same farms with MPN as 10 serum samples or 10 urine samples were collected from each farm. The serum was separated from the blood and the samples were then frozen at $-20^{\circ} \mathrm{C}$ until analysis.

\section{Mycotoxin extraction from feed samples and clean-up procedures}

A multi-mycotoxin extraction method (multi-mycotoxin screen) similar to that of Patterson and Roberts (1979) with some modifications was used to analyze the same feed samples from farms with nephropathy problems. Using the same method two extracts can be generated via an one step: neutral fraction (containing mainly: aflatoxins - $B_{1}, B_{2}, G_{1}, G_{2}$ and $\mathrm{M}_{1}$; trichothecenes - T-2 toxin, diacetoxyscirpenol, deoxynivalenol, fusarenon $\mathrm{X}$, nivalenol and their derivatives; zearalenone; patulin; sterigmatocystin; rubratoxin B) and acid fraction (containing mainly: citrinin, ochratoxin A, kojic acid, cyclopiazonic acid, penicillic acid). Most of the mycotoxins of interest (ochratoxin A, citrinin, penicillic acid, penitrem A, deoxynivalenol, zearalenone) were extracted using the same method and only extraction and clean-up of FB1 was performed by a separate procedure, because fumonisins are only soluble in lower alcohols and acetonitril and therefore required additional extraction step than other mycotoxins. The fumonisins extraction and clean-up was performed according to Hinojo et al (2006) using the SAX column.

\section{TLC analysis of feed extracts}

TLC (thin layer chromatography) analysis was performed according to Patterson and Roberts (1979) using two-dimensional thin layer chromatographic technique. Twenty microlitres of the neutral and acid fractions (dissolved in appropriate solvent - mainly dichloromethane) obtained from each feed sample were spotted on TLC plates (about $10 \mathrm{~mm}$ from the edge of a silica gel TLC plate) and dried in a warm stream of air. A similar procedure was followed for the standard mycotoxins. The spotted plates were then developed in TLC tanks using two solvents (mainly CEI and TEF for most of the mycotoxins; $\mathrm{CMA} / \mathrm{CM} 2$ and BWA for fumonisin $\mathrm{B} 1$, moniliformin or rubratoxin, $\mathrm{CtE}$ and $\mathrm{ChE}$ for zearalenone, etc $)^{\dagger}$ in two-dimensional directions and were dried after each development. The solvents move the toxins to the solvent front. The plates were visualized under ultraviolet (UV) light at 254 and $365 \mathrm{~nm}$ for the presence of any fluorescent or absorbing spot and were compared with the standard plates for each analyzed mycotoxin. In order to confirm the

\footnotetext{
${ }^{\dagger}$ CEI - Chloroform-Ethyl Acetate-Propan-2-ol (90:5:5 v/v/v)

TEF - Toluene-Ethyl Acetate-Formic Acid (6:3:1 v/v/v)

CM - Chloroform-Methanol (95:5 v/v)

CM2 - Chloroform-Methanol (3:2 v/v)

CMA - Chloroform-Methanol-Acetic acid (80:20:2 v/v/v)

BWA - Butanol-Water-Acetic acid (12:5:3 v/v/v)

CtE - Carbon tetrachloride-Ethanol (98:2 v/v)

ChE - Cyclohexane-Ether (3:1 v/v)
} 
identity of the mycotoxin, some plates were then sprayed with specific reagent for particular mycotoxin, such as Anisaldehyde for FB1, NH3-vapour for PA, Diazotised Benzidine for zearalenone (ZEA), Chromotropic acid for deoxynivalenol (DON) and other trichotecenes, Pauly's reagent for kojic acid (KA) or patulin (PAT), Ehrlich's reagent for cyclopiazonic acid (CA), etc. The $\mathrm{R}_{\mathrm{F}}$ (ratio of fronts) value for each spot was calculated and compared with the $\mathrm{R}_{\mathrm{F}}$. value of a standard for each mycotoxin.

A new substance (UM - unknown metabolite) with green fluorescence (Fig. 2), which was found to differ from all known mycotoxins and which was seen in almost all analyzed feed samples, was purified by repeated one-dimensional preparative TLC with alternating mobile phases (CEI and $\mathrm{CM})^{*}$ as silica (containing unidentified metabolite with green fluorescence) was scrapped from the plate into a flask, dissolved in acetone, filtered through Whatman No. 1 filter paper and dried by a rotory evaporator. The residues were reconstituted with dichloromethane (chloroform) and dried by passing through a stream of $\mathrm{N}_{2}$ gas until analyzed. For receiving enough quantity of the same substance, which was found also to be produced mainly by $P$. polonicum strain, a cultivation of the same species on solid media (as shredded wheat) and liquid media (as YES medium), and extraction via the mentioned above procedure was also performed.

\section{Liquid chromatography/mass spectrophotometry}

The mass spectrum of the purified extract of the UM was then determined by liquid chromatography/mass spectrophotometry (LC/MS) using Synapt HDMS Time-of-Flight mass spectrometer system equipped with Acquity-UPLC ${ }^{\mathrm{TM}}$ Sample Manager, Sample Organizer and Photodiode Array (PDA) UV detector (Waters, Milford, USA). An UPLC BEH $\mathrm{C}_{18}$ column $(2.1 \times 100 \mathrm{~mm}$ i.d, $1.7 \mu \mathrm{m}$ particle size $)$ was used in all chromatographic procedures. The sample compartments of the Sample Manager and Sample Organizer were cooled to $10^{\circ}$ C. The column heater was set at $40^{\circ} \mathrm{C}$ for all chromatographic experiments. The instrument was set to run in the positive ion mode with a capillary voltage $(3200 \mathrm{~V})$, sample cone voltage $(35 \mathrm{~V})$, resolution mass of 16,000 (W-mode), cone and desolvation gas flows of 50 and 450 $\mathrm{L} / \mathrm{h}$, respectively. In addition, source and desolvation temperatures were adjusted to 120 and $450{ }^{\circ} \mathrm{C}$, respectively. The mass spectrometer was calibrated using sodium formate (20 reference masses) and the calibration was checked daily using leucine enkephalin (50 pg/ml). Leucine enkephalin was also used as LockSpray reagent to ensure mass accuracy throughout the analysis process. The mass spectrometer was operated in $\mathrm{W}$ mode and all calibration data were collected as continuum data and deconvoluted using a mass range of $m / z$ 50-1500 amu. Raw data were collected as centroided data using MassLynx version 4.1 Software (Waters, Milford, USA). 
The purified TLC sample of investigated substance (UM) was dissolved in ultra-high purity methanol (Burdick \& Jackson, Honeywell, USA) and diluted further to obtain a suitable concentration level for analysis. The initial mobile phase consisting of ultra-high purity water (Milli-Q Advantage, Millipore USA) and ultra-high purity acetonitrile was pumped at a flow rate of $0.30 \mathrm{ml} / \mathrm{min}$. All solvents and samples were filtered through $0.22 \mu \mathrm{m}$ membrane of syringe filters prior to use. All infusion experiments were done by T-infusing the sample (in methanol) into the eluent stream consisting of water:methanol $(1: 1, \mathrm{v} / \mathrm{v})$ at a flow rate of $5 \mu \mathrm{l} / \mathrm{min}$. During the first infusion experiment, a complex mass spectrum was observed with mass ions ranging from $\mathrm{m} / \mathrm{z} 875$ to $\mathrm{m} / \mathrm{z} 149$ with the base peak observed at $\mathrm{m} / \mathrm{z}$ 413. MS-MS experiments were done to determine precursor - product ion relationships and to assist with structure elucidation of the compound. These experiments were set up to produce approximately a $50 \%$ fragmentation of the precursor ion and all masses lower than the selected precursor mass were monitored.

In an attempt to determine the best chromatographic conditions for the sample, $1 \mu \mathrm{l}$ injections were made while altering the eluent composition from $90 \%$ water: $10 \%$ methanol to 10\% water: $90 \%$ methanol. This experiment was also repeated by replacing the methanol with acetonitrile. As the compound of interest ionized in ESI positive mode, the addition of $0.1 \%$ formic acid to the water phase was also evaluated. To assist with the interpretation of the mass spectral data cationisation of the compound was attempted by T-infusing an aqueous $100 \mathrm{mM}$ potassium hydroxide at $1 \mu \mathrm{l} / \mathrm{min}$ just before the eluent stream entered the ESI probe.

Various experiments were done to determine if this UPLC-MS analysis procedure of 10 min (including the column equilibration step) could be shortened. Various gradient profiles and flow speeds between 0.3 and $0.6 \mathrm{ml} / \mathrm{min}$ were evaluated. The effect of cone gas on the ionisation process was also determined by varying the cone gas from $50 \mathrm{~L} / \mathrm{h}$ to $150 \mathrm{~L} / \mathrm{h}$.

\section{HPLC analysis of feed extracts}

All found mycotoxins of interest (via TLC method) in feed samples were then quantified using HPLC. HPLC analysis was performed using the system Shimadzu (Kyoto, Japan), consisting of liquid chromatograph LC 20A fitted to degasser DGU 20A3, auto sampler (injection) SIL 20A, communications bus module CBM 20A, column oven CTO 20A, photodiode array detector SPD M20A and fluorescence detector RF 10AXL all connected to gigabyte computer with Intel Core DUO with Microsoft XP. For HPLC analysis of PA, CIT, OTA, PenA and DON photodiode array (PDA) detector SPD M20A with column Waters Symetry C18 (250 mm long, $4.6 \mathrm{~mm}$ internal diameter) were used accordingly with appropriate mobile phase, flow rate and running time for each mycotoxin according to Kokkonen et al. (2005) and Abdulkadar et al. (2004) with little modifications. Reagents and 
HPLC conditions for the same mycotoxins were: mobile phase - acetonitril/water (50/50); flow rate $-0,8 \mathrm{ml} / \mathrm{min}$; injection volume $-10 \mu 1$ per sample; running time $-30 \mathrm{~min}$; column temperature $-30^{\circ} \mathrm{C}$. The differences in HPLC conditions for DON were: mobile phase acetonitril/water (15/85); flow rate $-1 \mathrm{ml} / \mathrm{min}$, running time $-20 \mathrm{~min}$.

For FB1 and ZEA analysis, RF-10AXL fluorescence detector (FD) was used with the same column and respective wavelength (excitation and emission), mobile phase, flow rate and running time for each mycotoxin. The settings of FD were: wavelength of $420 \mathrm{~nm}$ excitation and $500 \mathrm{~nm}$ emission for FB1, and $274 \mathrm{~nm}$ excitation and $418 \mathrm{~nm}$ emission for ZEA. Reagents and HPLC conditions for the same mycotoxins were: mobile phase acetonitril/water in the ratio $60 / 40$ for $\mathrm{FB} 1$ and $45 / 55$ for ZEA; flow rate $-1 \mathrm{ml} / \mathrm{min}$; injection volume - $10 \mu \mathrm{l}$ per sample; running time - $30 \mathrm{~min}$; column temperature $-30^{\circ} \mathrm{C}$. Derivatization reagent used for FB1 analysis was naphthalene dicarboxyaldehyde (NDA) and HPLC was performed according to Bennett and Richard (1994) - residues (sample and standards) were dissolved with $1 \mathrm{ml}$ methanol; into $100 \mu \mathrm{l}$ of sample or mycotoxin standard dissolved with methanol in HPLC vial, the following reagents were added in sequence and mixed after each addition: $100 \mu 10.05 \mathrm{M}$ sodium borate buffer ( $\mathrm{pH} 9.5$ ), $50 \mu 1$ sodium cyanide and $50 \mu \mathrm{l}$ NDA. This was followed by incubation in a water bath set at $50^{\circ} \mathrm{C}$ for 20 minutes, after which the samples were cooled and diluted with $700 \mu 10.05 \mathrm{M}$ phosphate buffer (pH 7)acetonitrile (40/60).

\section{HPLC analysis of serum and urine samples}

Extraction and HPLC analyses of ZEA and DON were performed according to Bily et al (2004), whereas those of CIT according to Wilkes and Sutherland (1998). PA was extracted and analysed according to Hanna et al (1981). OTA in serum was extracted and analyzed according to Boudra and Morgavi (2006), but in urine according to Fazekas et al (2005).

\section{Fungal screening and identification}

The Fungal screening and identification of all mycotoxin-analysed feed samples was also performed by the following mycological analytical procedures: fungal isolation on potato dextrose agar (PDA) and Ohio agricultural and experimental station agar (OAEA), subculturing on PDA, malt extract agar (MEA) and czapek yeast extract agar (CYA), macro- and microscopic identification. The final step involved: a) DNA extraction, b) PCR (polymerise chain reaction) amplification, c) purification of PCR product, d) product quantification and e) DNA sequence for a confirmation of various species of fungi.

For each feed sample a serial dilution technique was employed via which $1 \mathrm{~g}$ of each feed sample was diluted in $10 \mathrm{ml}$ ringer solution and vortexed, and subsequently $1 \mathrm{ml}$ of this suspension was transferred to $10 \mathrm{ml}$ ringer solution and vortexed, etc. One $\mathrm{ml}$ of each 
suspension was then aseptically inoculated on PDA and OAEA in Petri dishes and incubated at $25^{\circ} \mathrm{C}$ for 7-14 days. The culture method employed is according to that suggested by Klich (2002). From the fourth to the $7^{\text {th }}$ day, plates were screened for different types of fungal colonies, and counted using a colony counter. After incubation, the number of fungal colonies per gram of sample was calculated and expressed in colony forming units per gram (cfu/g). For the identification of fungal species, CYA, MEA and PDA were used. The hyphae and conidia from each colony representing each fungal species were transfered aseptically on three spots on PDA and incubated at $30^{\circ} \mathrm{C}$ for $7-14$ days for further identification. Determination of each species of fungi was done using the keys of Klich and Pitt (1988) and Klich (2002) for Aspergillus spp and Pitt and Hocking (1997) for Penicillium and Nelson et al. (1983) for Fusarium spp. This was done by observing both macroscopic characteristics of the colonies on various media used as well as the microscopic morphology under the microscope and measurements of the conidiophores (after staining mycelia with $0.1 \%$ fuchsin dissolved in lactic acid or with Lactophenol blue solution). The isolates were stored at $4^{\circ} \mathrm{C}$ for further uses and PCR analysis.

In a case where the morphological characteristics of individual fungal spp were not sufficient for clear identification, further analysis was performed. In addition, all isolated fungi were further identified via PCR analysis. The mycelia for PCR analysis were scrapped and transferred into a $0.5 \mathrm{ml}$ sterile screw-cap vial containing $200 \mu \mathrm{l}$ of ringer solution, freezedried and stored at $-40^{\circ} \mathrm{C}$ until analyzed. Fresh mycelia of some fungi was also used for PCR analysis in some cases. The technique involving the comparison of nucleic acid profiles of individual fungal species was employed using an automated sequencer. DNA extraction, PCR amplification, purification and quantification of PCR product, DNA sequencing and analysis were performed using similar technology as these described by Samson et al (2004) and Geiser et al (2004) with some modifications using Invisorb Spin Plant Mini Kit (Invitek GmbH, Robert-Rossle-Str. 10, D-13125, Berlin) for DNA extractions from plant material (fresh, frozen or dried materials) in addition to $\mathrm{MSB}^{\circledR}$ Spin PCRapace for ultrafast purification and concentration of PCR-fragments (Invitek GmbH, Robert-Rossle-Str. 10, D13125, Berlin). This PCR process is covered by U.S. Patents 4,683,195 and 4,683,202 owned by Hoffmann-LaRoche AG. Samples were further analyzed on an ABI PRISM 3700 Genetic analyzer (AB, Applied Biosystems, Nieuwerkerk a/d Yssel, The Netherlands). The forward and reverse sequences of the PCR products were assembled with a DYEamic ET Terminator Cycle Sequencing Kit (Amersham, Bioscience, Roosendaal, Netherlands) using the programmes SeqMan and EditSeq from the LaserGene package (DNAStar Inc. Madison, WI). 
The PCR analysis was performed in Inqaba Biotec in Pretoria (South Africa) as Inqaba Finch server was used for DNA sequencing and identification of fungi.

\section{Determination of mycotoxinogenic potentials of isolates}

All identified fungal species were further analyzed for their capability to produce various mycotoxins. The isolates were individually cultured on YES agar in Petri dishes and incubated at $25^{\circ} \mathrm{C}$ for two to three weeks according to the method of Singh et al. (1991). A thin layer chromatography technique was then employed whereby $5 \mathrm{~g}$ of isolate including the medium was plugged and dissolved in $10 \mathrm{ml}$ of dichloromethane. This solution was further filtered, and the filtrate put in a screw-cap vial and dried under a stream of $\mathrm{N}_{2}$ gas and stored at $4^{\circ} \mathrm{C}$ until analyzed. The same two-dimensional thin layer chromatographic technique (Patterson and Roberts, 1979) was employed for the detection of mycotoxins.

\section{Chemicals and mycotoxins}

Mycotoxins: The standard of all analysed mycotoxins were obtained from Sigma Bioscience (St Louis, USA) or Merck \& Co and only the standard for penicillic acid (PA) was obtained from A.G. Scientific, Inc. (San Diego, CA, U.S.A.).

All solvents for HPLC analysis were HPLC grade and were obtained from Merck, Darmstadt, Germany. All chemicals for PCR analysis were purchased from Invitek GmbH (Invitek GmbH, Robert-Rossle-Str. 10, D-13125, Berlin).

\section{Statistical analysis:}

The Student's t-test was used to calculate the mean values and standard error of the mean of various parameters as appropriate.

\section{RESULTS}

Our investigations in the farms with porcine/chicken nephropathy showed that the same farms usually had a history of incorrect feed storage. In a few cases, the problem seemed to come from certain feed plants whose grains, collected during moist and rainy days, had not been properly dried. All farms supplied by these plants subsequently produced some pigs/chickens with nephropathy and growth depression, but after changing the suspected feeds the problems with poor growth of pigs/chickens disappeared. As a whole, the frequency and duration of the observed nephropathy in different batches of slaughtered pigs/chickens varied significantly (from $1-2 \%$ up to $80-90 \%$ frequency) and have depended on the duration of feeding of various suspected feeds stored for a long time in poor conditions and at high humidity. That nephropathy (mottled or enlarged and pale kidneys) was established during the meat inspection at slaughter time (Figure 1). 
TLC analysis of feed extracts, prepared via multi-mycotoxin extraction procedure from feed samples originated from farms with porcine/chicken nephropathy, revealed presence of the following mycotoxins in most of the feed samples: OTA, PA, CIT, FB1, PenA, DON and ZEA. Therefore, these feed extracts were analyzed for the same mycotoxins via HPLC method allowing quantification of these mycotoxins in feed samples (Table 1). Contamination levels of OTA were low $(188.8 \pm 27.3 \mu \mathrm{g} / \mathrm{kg})$ in contrast to high contamination levels of FB1 $(5564.1 \pm 584.4 \mu \mathrm{g} / \mathrm{kg})$ and PA $(838.6 \pm 223.9 \mu \mathrm{g} / \mathrm{kg})$.

HPLC analysis of serum and urine samples from pigs with MPN, originated from MPNaffected farms, revealed also presence of some of these mycotoxins (Table 2, Table 3).

A new secondary fungal metabolite (UM) with green fluorescence (Fig. 2), which was seen to differ from all known mycotoxins by its fluorescence and $\mathrm{R}_{\mathrm{F}}$ values, was found in 23 feed extracts ( $92 \%$ of the feed extracts). The same substance, which was purified as described in Materials and Methods will be further studied for cytotoxic effect on human lymphocytes in some other experiments. It was established that this UM produced an UV spectrum which shows the molecule can be detected at maximum wavelength of $204 \mathrm{~nm}$. The spectrum also confirmed the purity of the molecule.

Fungal analysis revealed a heavy contamination with Gibberella fujikuroi var. moniliformis (Fusarium verticillioides) as all isolated species were able to produce FB1. Similarly, a heavy contamination with Penicillium aurantiogriseum complex (mainly Penicillium polonicum), which appeared to be a good producer of PA and UM was also observed in almost all examined feed samples (92\%) coming from pig- and chick farms with nephropathy problems in Bulgaria. In contrast, a light contamination with the most usual producers of OTA (Aspergillus ochraceus, Penicillium verrucosum) and citrinin (Penicillium citrinum) was observed in the same feed samples and these species were isolated as very rare component of the mycobiota. Some of the A. niger, A. wentii, P. commune and A. fumigatus species were also found to produce small amount of OTA (Table 4a). Some rare isolates were also seen to produce UM (Table $4 \mathrm{~b}$ ).

As can be seen from the table, the UM was found to be produced by a large range of species, but mainly by $P$. polonicum. The initial infusion experiments with this metabolite produced a complex spectrum with a base peak ion observed at $m / z$ 413. The mass spectrum of the main compound of interest shows the base peak changed to $m / z, 803$ only when a highly aqueous mobile phase (90\% aqueous) was used. On the other hand, when the aqueous content of the mobile phase was changed, a shift back to a base peak of $m / z, 413$ was observed and it remained the base peak in all the water:methanol solvent compositions tested. In the experiments where the methanol was replaced with acetonitrile, the compound with a base 
peak at $m / z 803$ was not observed and in all solvent ratio's evaluated (10\% acetonitrile to $90 \%$ acetonitrile) only the compound with the base peak at $\mathrm{m} / z 413$ was observed.

The UM was found to be soluble in methanol, acetone and dichloromethane. Methanol was selected as the best solvent for the compound. It was seen that the compound ionized the best with methanol as organic modifier and that the presence of acetonitrile suppressed ionization when compared with methanol. The addition of formic acid did not contribute to the ionization process as no significant change in mass ions was observed. Therefore, formic acid was omitted from the mobile phase and the optimized method utilized only water:methanol.

The optimized chromatographic and mass spectrometric method was utilized to elucidate the mass and the possible structure of the UM. The fact that the compound did not show any increase in ionization with the addition of formic acid to the eluent, suggests that the compound contains no nitrogen or at least no nitrogen that can be ionized. The addition of potassium afforded the formation of a new base peak with $\mathrm{m} / \mathrm{z} 429$ and a related peak at $\mathrm{m} / \mathrm{z}$ 819. The previous base peak at $\mathrm{m} / \mathrm{z} 413$, observed in the absence of potassium, as well as its related peak at $m / z$ 803, were also present but in low abundance with a mass difference of 390 between the two sets of associated peaks. By discontinuing the infusion of potassium the mass spectrum of the compound reverted back to the original base peak and its associated mass ion (413 and 803). The results found confirmed the presence of cationisation with the mass ions at $m / z, 413$ and 429 to be $[\mathrm{M}+\mathrm{Na}]^{+}$and $[\mathrm{M}+\mathrm{K}]^{+}$, respectively, thus giving the molecular mass of this novel metabolite as 390. This mass also provides the difference between the base peak mass ions and their associated higher mass ions, an indicative of dimer formation.

By interpreting the TOF MS and MS MS analysis data and ascertaining if the compound is forming some adducts it was established the molecular mass of the novel metabolite (390.27701). The tendency of the compound to undergo cationisation with sodium or potassium was also confirmed in some further experiments.

\section{DISCUSSION}

The $\mathrm{m} / \mathrm{z}$ of UM does not correspond with those of the penitrems provided by Kyriakidis et al. (1981) and metabolites of other Penicillium cultures provided by Smedsgaard and Frisvad (1996), Smedsgaard (1997) and Smedsgaard and Nielsen (2005). It can therefore be said that the novel mycotoxin cannot be assigned to any known metabolite reported in literature. The full set of NMR spectra only remain to be performed in order to determine the structure of UM. 
The absence of PenA in most of the serum or urine samples could be due to the lack of a direct connection between the feed samples and blood or urine samples, because the feed sampling is always retrospective and sometimes the feed sources of the affected farms have been recently changed. On the other hand feed deprivation of pigs before slaughtering could eliminate PenA and especially FB1 from the blood. It is known that fumonisins have a poor absorption and a rapid excretion mainly through the faeces (via the liver) rather than the urine and it is unusual to discover this mycotoxin in pig blood (Taranu et al., 2008), especially after the feed deprivation of pigs before slaughtering. That was the reason why the study of FB1 in the blood was omitted.

Also, it is difficult to assess the content of various mycotoxins in the grounded feeds because the fungi invade only a minor fraction of feed particles with appropriate condition for a growth of fungi. Thus, the mycotoxin's contamination of feedstuffs in two nearly situated places is markedly different. That could explain why some of the mycotoxins can be only found in small number of blood or urine samples of the pigs from the same farm.

Analyzing the results obtained, it becomes clear, that the overall concentration of OTA in feed samples were substantially lower than the levels $1-2 \mathrm{mg} / \mathrm{kg}$ required to reproduce MPN/MCN of severity similar to that observed in spontaneous cases (Krogh, 1976; Stoev et al., 1998a,b, 2002a). It seems, therefore, that the MPN/MCN in Bulgaria may have a multitoxin or multi-factor aetiology, because it cannot be explained by the concentration of OTA alone and the respective OTA producing fungi (P. verrucosum and A. ochraceus) found in the feeds from farms with nephropathy problems. The multi-mycotoxin aetiology of MPN/MCN in Bulgaria was clearly confirmed by the present investigations according to which high mean contamination levels of PA (838.6 - $904.9 \mu \mathrm{g} / \mathrm{kg})$ and FB1 $(3254.5$ - $5564.1 \mu \mathrm{g} / \mathrm{kg})$ in Bulgarian feed samples from farms with MPN/MCN were found in addition to consecutively low mean levels of OTA $(188.8-376.4 \mu \mathrm{g} / \mathrm{kg})$ in the same feeds. It is also important to mention that the percentage of feed contamination with PA and FB1 was constantly high above $88 \%$. The same multimycotoxin etiology was recently found for South African MPN as the same mixture of mycotoxins $(67.8 \pm 39.2 \mu \mathrm{g} / \mathrm{kg}$ OTA $-83.3 \%$ positives; $149.2 \pm 64.1$ $\mu \mathrm{g} / \mathrm{kg}$ PA $-41,7 \%$ positives, $5046.2 \pm 1301 \mu \mathrm{g} / \mathrm{kg}$ FB1 $-80 \%$ positives) was established in South African feed samples from pig farms with nephropathy problems (Stoev, 2008b). Only the levels of OTA and PA were 2-3 times lower (unpublished data).

Obviously, the best model for Bulgarian nephropathy is the renal disease that was previously investigated in depth in Denmark and shown conclusively to be caused by nephrotoxins of fungal origin (mainly OTA and CIT produced by Penicillium verrucosum growing on poorly stored feed or grain). However, in the Bulgarian nephropathy the incidence 
of OTA measured in the diet, in serum and in kidney tissues was much less than should be necessary (according to extensive experimentation in Denmark) fully to account for the renal changes (Stoev et al., 1998a,b,c, 2002a). According to the different macroscopic and microscopic changes as well according to the different stages of the progress of the observed nephropathy it was made a classification of the kidneys damages in pigs (Stoev et al., 1998a). The examinated kidneys were classified in five separated groups: "mottled kidneys", "enlarged and marbled kidneys", "enlarged pale kidneys", "cystic kidneys" and "fibrotic kidneys". The pathology in the last two groups of kidneys is not characteristic for nephropathy ranged in Scandinavian countries. The differences in macroscopical and microscopical picture of kidney were considered to be due to the differences in the length of the time of exposure to the mouldy feed (Stoev et al., 1998a) as well as to the differences in the amount or combination of nephrotoxic mycotoxins ingested by each pig.

It is now clear that all difference between classic Danish porcine/chicken nephropathy and Bulgarian nephropathy in pigs (e.g. enlargement of renal lymph nodes, neoplastic changes, significantly enlarged and marbled or pale appearance of kidneys as well as cystic or stronger fibrotic changes in cortex of the kidneys) as described recently in the Veterinary record's paper (Stoev et al., 1998a) and chickens (e.g. nervous symptoms, vascular and oedematous changes in various internal organs and the brain, and subcutaneous or liver and kidney haemorrhages in addition to known degenerative changes in the kidneys, liver and lymphoid organs) as described in Veterinary Research's paper (Stoev et al., 2002a) are probably a result of the effects of other nephrotoxic metabolites as PA, FB1 and PenA (probably responsible for nervous symptoms) in addition to the toxic effect of OTA or may be attributed to synergistic effects between OTA and other mycotoxins, and the increase of OTA-toxicity (Stoev, 2008b).

A synergistic effect between OTA, CIT and FB1, has been seen in some "in vivo" or "in vitro" studies. OTA and FB1 were reported to induce "in vitro" and "in vivo" degenerative and apoptotic changes in rat kidney (Dragan et al., 2001; Petrik et al., 2003). A synergistic effect between OTA and FB1, which was proved "in vitro" (Klaric et al., 2007; Creppy et al., 2004) is in line with some "in vivo" data from the literature (Kubena et al., 1997). Moreover, the DNA damage provoked by the combined treatment with OTA and FB1, measured either by the standard comet assay or Fpg-modified comet assay, showed a synergistic increase in kidney cells "in vivo" as indicated by the tail length, tail intensity and OTM (olive tail moment), even at doses that correspond to the daily human exposure in Europe (Domijan et al., 2006). In the same experiment, the tail intensity and OTM of the kidneys cells of rats receiving combined treatment of OTA and FB1 was much higher than would be a simple sum 
of values caused by the respective doses of either mycotoxin alone. It was also shown that the oxidative stress is not only the mechanism in DNA damages, provoked by OTA and FB1 alone or together (Domijan et al., 2006).

Another report for a synergistic effect between some of the target mycotoxins is made by Lillehoj and Ceigler (1975), who give an example where PA and CIT were innocuous when administered alone, but were $100 \%$ lethal when given in combination.

A synergistic effect has been also seen between OTA and CIT in the suppression of Concavalin A-induced proliferation of porcine lymphocyte (Bernhoft et al., 2004). A similar synergistic effect between these mycotoxins has been reported also in "in vivo" studies with poultry, rodent and dogs (Koshinsky and Khachatourians, 1994) as well as simultaneously in both "in vivo" and "in vitro" studies as the co-treatment with OTA and CIT has been observed to increase the major adduct formed by OTA (Pfohl-Leszkowicz et al., 2008). Simultaneous administration of OTA and CIT also enhanced the incidence of renal cell tumours in mice (Kanisawa, 1984).

Because of the potent toxic and synergistic effects between OTA and PA or CIT (Sansing et al., 1976; Stoev et al., 2001; Bernhoft et al., 2004) as well as between OTA and FB1 (Klaric et al., 2007; Creppy et al., 2004), simultaneous exposure to those mycotoxins might be of significant importance and could be crucial for development of chronic renal failure observed in MPN or BEN, especially after long-term ingestion of the same mycotoxins. An important question then arises, whether such a combination of mycotoxins is occurring in food and feed and if yes what the ranges are. It should be emphasized that there is only scarce information about the contamination levels of PA and FB1 in foods or feeds from MPN- and BEN-endemic areas, because extensive studies have not been performed. It has only been reported that FB1 and OTA co-occurred in maize in Croatia (Jurjevic et al., 1999, 2002; Domijan et al., 2005) as the mean levels of FB1 $(459.8 \mu \mathrm{g} / \mathrm{kg})$ found in the last study (Domijan et al., 2005) are not of little significance. High contamination levels of OTA and FB1 (up to $40 \mathrm{mg} / \mathrm{kg}$ ) have been also found in some pig feeds (Diaz et al., 2001) and were reported to provoke the death of the same pigs as pathological picture revealed pathological signs of both toxins, e.g. pulmonary oedema, liver and kidney lesions.

On the other hand, OTA and CIT (Vrabcheva et al., 2000) in addition to OTA and PA (Stoev et al., 2002a) are often present in human or animal foods/feeds in Bulgaria originated from BEN-endemic areas or from farms with mycotoxic porcine/avian nephropathy as can be seen in the present study. Moreover, the feed levels of the same mycotoxins are not so low in order to be neglected and the amount of CIT has been often ten times higher in bean or maize from BEN-affected families compared to the nonaffected ones (Vrabcheva et al., 2000). Some 
recent investigations also confirmed the implication of OTA and CIT in BEN, because DNA adducts related to OTA (Castegnaro et al., 2006) and CIT (Pfohl-Leszkowicz et al., 2007) were found in human kidney tissues from BEN-endemic areas, and both mycotoxins were present in high percent of investigated food/wheat samples as well as in the urine of families with BEN (Castegnaro et al., 2006; Pfohl-Leszkowicz et al., 2007). In addition, the comparative ten-year follow-up study of OTA exposure in an BEN endemic village in Croatia clearly showed higher frequency of OTA-possitive food and serum samples than in control village (Fuchs and Peraica, 2005). OTA was also more frequent and at higher levels in blood samples from patients with BEN and urinary tract tumours compared to non-affected ones (Fuchs and Peraica, 2005).

The synergism in cytotoxicity of FB1 and OTA could be related to the ability of both toxins to impair protein synthesis and to increase lipid peroxidation producing reactive oxygen species (Creppy et al., 1984; Rahimtula et al., 1988; Abado-Becognee et al., 1998). Due to the fact that these toxins are increasing reactive oxygen species production, the feeding animals with diet containing antioxidants may provide a good prevention means (Creppy et al., 2004; Stoev et al., 2002c).

On the other hand some rare and slightly nephrotoxic mycotoxins as XA, CA, ERY and RUB can also have an additional synergistic or additive nephrotoxic effects in addition to already mentioned mycotoxins as the same are found in some of the feed samples from farms with MPN (see Tables 4a,b).

Our recent investigations on the cytotoxic effect of different combinations of OTA, PA, CIT and FB1 on human peripheral blood mononuclear cells measured by MTT assay revealed additive or synergistic effects of the following mycotoxins: OTA, CIT and FB1 as compared to any single mycotoxin (Stoev et al., 2009). In the same experiment, there was not observed "in vitro" synergistic effect between OTA and PA, which can be explained by the specific mechanism of "in vivo" synergistic effect of both mycotoxins and MTT assay being inappropriate for cytotoxic evaluation of PA as the same mycotoxin increases metabolic activity of cells. It is important to recognize that "in vitro" experiments can mainly demonstrate direct synergistic effects of mycotoxins, but only "in vivo" studies can clearly show the real interaction between mycotoxins in addition to their absorbtion, distribution, bioavailability, metabolism and excretion. Therefore, it is already of great importance to determine whether feeding such mycotoxin contaminated mouldy feed to pigs/chicks could reproduce the same functional and morphological changes in kidneys observed in spontaneous porcine/chicken nephropathy at contamination levels and periods corresponding to the levels and periods of exposure to feed naturally contaminated with the same 
combination of mycotoxins. In addition, it will be helpful to establish, whether the same combination of mycotoxins has a real synergistic effect as this one between PA and OTA (Stoev et al., 2001, 2004).

It has to be emphasized that pathomorphological changes in kidneys in spontaneous MPN in Bulgaria, including fibrotic changes and contraction of kidneys in later stages of MPN, resemble much more to those in BEN in humans, than in Danish MPN (Stoev, 1998), Moreover, there are many other striking similarities between BEN in humans and Bulgarian MPN as the low food/feed concentrations of OTA, various kind of tumours in kidneys (pigs) or urinary tract (humans), retention tubular cyst formations, vascular damages, electron dense formations or myelin-like figures in mitochondria of epithelial cells. The same damages have not beeen seen in classical MPN as described in Scandinavian countries or elsewhere. All these discrepancies between Bulgarian MPN and classical MPN, in addition to the similarities between Bulgarian MPN and BEN, could be due to the interaction between OTA and other mycotoxins, which needs to be further proved. Our arguments can be also supported by some recent experiments, in which we found electron-dense formations and myelin-like figures in kidneys of pigs exposed to very low contamination levels of OTA together with PA. The same damages resemble much more to those in spontaneous MPN and are unusual for classical Danish MPN (Stoev et al., 2001).

On the other hand, FB1 (Gelderblom et al., 1992; Howard et al., 2001) and PA (Dickens and Jones, 1961; Palmgren and Ciegler, 1983) were found to be carcinogenic mycotoxins and may interact in this dimension with OTA, which is also proven carcinogen. Moreover, FB1 was found to have a pronounced nephrotoxic effect on animal kidneys (Voss et al., 2001; Bucci et al., 1998), which can be additive to nephrotoxic effect of OTA.

Some recent experiments clearly showed that the toxicity of various strains of the same Aspergillus ochraceus group is completely different, depending on their capacity to produce both mycotoxins: OTA and PA. A stong synergistic effect was reported for the both mycotoxins: OTA and PA, when the same were given simultaneously to pigs or chicks (Micco et al., 1991; Stoev et al., 1999, 2000a, 2001, 2004). It was shown that such low contamination levels of OTA as $180 \mu \mathrm{g} / \mathrm{kg}$, together with PA can induce macroscopic kidney damages similar to spontaneous MPN only after 3 months of exposure (Stoev et al., 2001). Degenerative and weight changes in kidneys, liver and lymphoid organs similar to spontaneous MCN as well as immunosuppression were also observed in chickens at only 0.2 or $0.3 \mathrm{mg} / \mathrm{kg}$ OTA in combination with PA (Stoev, 2000; Stoev et al., 1999, 2000a, 2004). Similar changes in chickens can be only provoked by ingestion of significantly higher contamination levels of pure OTA (about $4 \mathrm{mg} / \mathrm{kg}$ ) in feed (Dwivedi and Burns, 1984; 
Manning and Wyatt, 1984). The low experimental levels of OTA used in the mentioned above experiments are very similar to the feed levels of OTA found in spontaneous cases of porcine/chicken nephropathy in Bulgaria $(90-310 \mu \mathrm{g} / \mathrm{kg})$, which also supports the multicausal nature of animal nephropathy in Bulgaria (Stoev et al., 1998a; 2002a). The increase in OTAtoxicity in these cases is shown to be due to the partially impaired detoxification of OTA by PA, when both mycotoxins are ingested by animals (Micco et al., 1991; Stoev et al., 1999, 2000a, 2001, 2004). Such a multiple mycotoxin production by a single fungus, such as Aspergillus ochraceus (which produces OTA and PA simultaneously), or by several fungi, appeared to be a significant problem that has not been sufficiently investigated. Such mixtures of mycotoxins may have synergistic or at least additive effects in farm animals, which could explain why the low levels of OTA in the feeds for pigs (Stoev et al., 1998a,b), chickens (Stoev et al., 2002a) or humans (Stoev, 1998) may have such a potent toxic effect on kidneys, when received simultaneously with other mycotoxins via spontaneous mouldy feeds.

It is important to mention that FB1 may also contribute to the immunosuppressive effect of OTA and the increase in secondary bacterial infections observed in pigs with spontaneous MPN (Stoev et al., 2000a,b), because an increase of intestinal colonization by pathogenic E. coli has been found in FB1-treated pigs (Oswald et al., 2003).

The previous mycological investigations of OTA-contaminated feeds in Bulgaria showed the common presence of $P$. aurantiogriseum complex (Stoev et al., 1998a), which can be a potent producer of PA (Rubiales et al., 1998). The same mycotoxin is usually produced by numerous species of Penicillium (mainly P. aurantiogriseum) and Aspergillus at temperature between $4^{\circ} \mathrm{C}$ and $30^{\circ} \mathrm{C}$, with the maximum production at about $25^{\circ} \mathrm{C}$ (Le Bars, 1980). The production of PA usually decreases significantly with decreasing of oxygen concentrations in contrast to the fungal growth, which is slightly influenced (Northolt, 1979). PA can form progressively complexes with compounds containing - SH radicals (Lieu and Bullerman, 1977, 1978), which significantly increases with $\mathrm{pH}$ as well as in high temperature (Lieu and Bullerman, 1978). These complexes are less toxic than the uncoupled molecules, which results in actual detoxification. That is why, PA usually accumulates at relatively low temperatures during the winter, when actual detoxification is more restricted than toxin production (Le Bars, 1980). That could be a good explanation for the time of observing this nephropathy in Bulgaria - during the spring or summer periods (after the winter).

It is important to mention, that our results are in good agreement with those earlier reported by Miljkovic et al. (2003), who found that administration of P. polonicum extract (not containing OTA or other known mycotoxins) to rats can provoke significant and persistent pathomorphological changes in the nuclei of tubular epithelium in kidneys of rats 
such as apoptosis and karyomegalic or mitotic changes, including DNA-adducts formation. This $P$. polonicum strain, which is a common food/feed spoilage mould in warm temperate areas, was found to be a frequent contaminant in Bulgarian feeds, suspected of causing spontaneous MPN (Mantle and McHugh, 1993; Stoev et al., 1998a). That P. polonicum extract given to rats by Miljkovic et al. (2003) could also contain PA, because the strains from $P$. aurantiogriseum group (including P. polonicum) are potent producers of PA. Moreover, PA can also provoke DNA breaks in mammalian cell lines as has been previously reported (Umeda et al., 1972). Therefore, it could appear that the main source of PA in Bulgarian feeds can be different from the source of OTA. The same changes (apoptosis and karyomegaly in tubular epithelium), provoked by $P$. polonicum extract, could be also induced by the same UM found in the present study, which need to be further proven. It seems, that UM could be partly responsible for the nephrotoxic damages described in Bulgarian animal or human nephropathy, which etiology remains not thoroughly clear. Our recent experiment (Njobeh et al., 2009) suggests a potent cytotoxicity of the purified UM. Moreover, the quiet apoptosis, induced by the same UM of $P$. polonicum extract, could be also partly responsible for the cryptic and clinically-silent onset of renal atrophy in the idiopathic BEN in humans (Mantle et al., 1998). The provoked by UM apoptic changes could couple with apoptic changes, which can be provoked by OTA. It is known that OTA can also provoke apoptic changes as well as DNA-adducts “in vitro" (Obrecht-Pflumio and Dirheimer, 2000, 2001) and "in vivo" (Atroshi et al., 2000; Faucet et al., 2004), and that mycotoxin was considered to be responsible for the DNA-adducts in the urinary tract tumors of patients with BEN (Pfohl-Leszkowicz et al, 1993, 2007). Therefore, the interaction between OTA and other co-contaminants in commercial chicken/pig rations or human food would be very important and could explain the significance of the relatively lower doses of OTA that commercial chickens (Stoev et al., 2000a, 2002a), pigs (Stoev et al., 1998a,b) or humans (Stoev, 1998) may ingest via the feed/food. Particular attention have to be paid to the high incidences of these Penicillium spp. (especially P. polonicum) responsible for the high contamination levels of this UM in animal and human feed/food. It is essential to study other potential biological effects of the UM on mammalian cells in further "in vivo" or "in vitro" studies. In addition, further investigations, including nuclear magnetic resonance, must be also undertaken in order to clarify the chemical structure of UM.

In addition to $P$. pollonicum, some other Penicillium fungi as $P$. aurantiogriseum and $P$. commune were also found to be nephrotoxic to rats (Macgeorge and Mantle, 1990) or to kidney tubule cells in tissue culture (Yeulet et al., 1988). These fungi were isolated from maize collected from BEN-endemic areas of former Yugoslavia and athors conclude that the 
same fungi produce biologically active fraction or secondary metabolite (unknown mycotoxin), which could be a possible factor in the aetiology of BEN. The toxicity of this compound is a little similar to that of OTA and the target place was concluded to be the P3 segment of proximal tubules of kidneys. Such fungi were also isolated from MPN-endemic areas in Bulgaria 10 years ago (Stoev et al., 1998) as well as in our last study. As can be seen in this study, we managed to isolate such a substance from the same Penicillium fungi, isolated from MPN-endemic areas in Bulgaria. The same substance was recently purified and studied for possible cytotoxic effect on human lymphocytes in comparison to other mycotoxins as OTA and T-2 toxin and its toxicity at low concentrations $(0.15,0.31$ and 0.63 $\mu \mathrm{g} / \mathrm{ml}$ ) was found to be lower than toxicity of OTA, but a little similar to that of T-2 toxin (Njobeh et al., 2009).

In the present study it became clear, that the synergism between OTA and various other mycotoxins such a PA, CIT, FB1 and not yet chemically identified $P$. polonicum nephrotoxin in field conditions may be responsible for an enchanged toxicity of OTA. Due to the potent toxic and synergistic effects of OTA and PA or CIT (Stoev et al., 2001; Bernhoft et al., 2004) as well as between OTA and FB1 (Klaric et al., 2007; Creppy et al., 2004), simultaneous exposure to those mycotoxins might be an important factor for development of chronic renal diseases in animals and humans as this one in Bulgaria, especially after long-term exposure. It also seems that in a diverse human diet, exposure to multiple mycotoxins at a low concentration on an intermittent rate over long period of time may also cause toxic damages in kidneys. It is therefore of great importance to investigate the real toxic effect of combined administration of OTA and other mycotoxins, as it is occurred in the real field conditions.

In addition to various synergistic effects between target mycotoxins, we must have in mind the specific characteristics of each mycotoxin as its transfer to the milk or through the placenta to the foetus as well as its bioavailability and degree of binding with plasma proteins (Pfohl-Leszkowicz and Manderville, 2007) in order to establish its potential risk for animals or humans.

On the other hand, only integrated approach to food safety, which includes systematic identification and assessment of hazards in foods/feeds and various means to control them, could resolve the existing problems in this field. Effective enforcement of food safety laws and regulations in addition to surveillance control is also required to reduce the number of food-borne diseases as well as to enhance foods/feeds security. That's why a harmonization of various national standards in regards to various mycotoxins and their combinations is also necessary in order to protect the consumer and to ensure a global safety of various kinds of foods/feeds produced in various countries. 


\section{Acknowledgements:}

This research has been financially supported in part by Marie Curie Outgoing International Felowship within $6^{\text {th }}$ European Community Framework Programme, Department of Science and Technology in South Africa, UK Royal Society Joint Project with Central and Eastern Europe and Foundation of Ministry of science and education of Bulgaria via 5 Research projects.

\section{REFERENCES}

Abado-Becognee K, Mobio TK, Ennamany R, Fleurat-Lessard F, Shier WT, Badria F, Creppy EE. 1998. Cytotoxicity of fumonisin B1: implication of lipid peroxidation and inhibition of protein and DNA syntheses. Arch Toxicol. 72: 233-236.

Abdulkadar AHW, Al-Ali AA, Al-Kildi M, Al-Jedah JH. 2004. Mycotoxins in food products available in Qatar. Food Control. 15: 543-548.

Atroshi F, Biese I, Saloniemi H, Ali-Vehmas T, Saari S, Rizzo A, Veijalainen P. 2000. Significance of apoptosis and its relationship to antioxidants after ochratoxin A administration in mice. J Pharm Pharmaceut Sci. 3: 281-291.

Bennett GA, Richard JL. 1994. Liquid Chromatographic method for analysis of the naphthalene dicarboxaldehyde derivative of fumonisins. J Assoc Off Anal Chem Int. 77 (2): 501-506.

Bernhoft A, Keblys M, Morrison E, Larsen HJS, Flåøyen A. 2004. Combined effects of selected Penicillium mycotoxins on "in vitro" proliferation of porcine lymphocytes. Mycopathologia. 158: 441-450.

Bily AC, Reid LM, Savard ME, Reddy R, Blackwell BA, Campbell CM, Krantis A, Durst T, Philogene BJR, Arnason JT, Regnault-Roger C. 2004. Analysis of Fusarium graminearum mycotoxins in different biological matrices by LC/MS. Mycopathologia. 157: 117-126.

Boudra H, Morgavi DP. 2006. Development and validation of a HPLC method for the quantitation of ochratoxins in plasma and raw milk. J Chromatogr B. 843: 295-301.

Bucci TJ, Howard PC, Tolleson WH, Laborde JB, Hansen DK. 1998. Renal effects of fumonisin mycotoxins in animals. Toxicol Pathol. 26: 190-194.

Castegnaro M, Canadas D, Vrabcheva T, Petkova-Bocharova T, Chernozemsky IN, PfohlLeszkowicz A. 2006. Balkan endemic nephropathy: Role of ochratoxin A through biomarkers. Mol Nutr Food Res. 50: 519-529. 
Chan PK, Hayes AW. 1981. Effect of penicillic acid on biliary excretion of indocyanine green in the mouse and rat. J Toxicol Environ Health. 7: 169-179.

Creppy EE, Röschenthaler R, Dirheimer G. 1984. Inhibition of protein synthesis in mice by ochratoxin A and its prevention by phenylalanine. Food Chem Toxicol. 22: 883-886.

Creppy EE, Chiarappa P, Baudrimont I, Borracci P, Moukha S, Carratù MR. 2004. Synergistic effects of fumonisin $\mathrm{B}_{1}$ and ochratoxin A: are "in vitro" cytotoxicity data predictive of "in vivo" acute toxicity. Toxicology. 201: 115-123.

Diaz CT, Sogbe E, Ascanio E, Hernandez M. 2001. Ochratoxin A and fumonisin B1 natural interaction in pigs. Clinical and pathological studies. Rev Cient Fac Cien. V: 314-321.

Dickens F, Jones HEH. 1961. Carcinogenic activity of a series of reactive lactones and related substances. Br J Cancer. 15: 85-100.

Domijan A, Peraica M, Jurjevic Z, Ivic D, Cvjetkovic B. 2005, Fumonisin B1, fumonisin B2, zearalenone and ochratoxin A contamination of maize in Croatia. Food Add Contam. 22 (7): 677-680.

Domijan A, Zeljezic D, Kopjar N, Peraica M. 2006. Standard and Fpg-modifed comet assay in kidney cells of ochratoxin A-and fumonisin B1-treated rats. Toxicology 222: 53-59.

Doster RC, Sinhuber RO. 1972. Comparative rates of hydrolysis of ochratoxin A and B "in vitro". Food Cosmet Toxicol. 10: 389-394.

Dragan YP, Bidlack WR, Cohen SM, Goldsworthy TL, Hard GC, Howard PC, Riley RT, Voss KA. 2001. Implications of apoptosis for toxicity, carcinogenicity, and risk assessment: fumonisin B1 as an example. Toxicol Sci. 61: 6-17.

Dutton MF, Kinsey A. 1995. Incidence of mycotoxins and fungi in feedstuffs in Natal in 1995. Mycopathologia. 131: 31-36.

Dwivedi P, Burns RB. 1984. Pathology of ochratoxicosis A in young broiler chicks. Res Vet Sci. 36 (1): 92-103.

Elling F. 1977. Demonstration of ochratoxin A in kidneys of pigs and rats by immunofluorescence microscopy. Acta Path Microbiol Scand Sect A. 85: 151-156.

Elling F, Nielsen JP, Lillehoj EB, Thomassen MS, Stormer FC. 1985. Ochratoxin A induced porcine nephropathy: enzyme and ultrastructural changes after short-term exposure. Toxicon. 23: $247-254$.

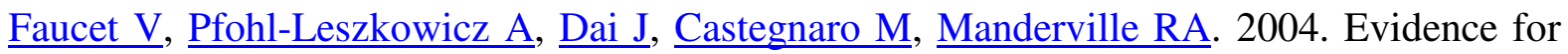
Covalent DNA Adduction by Ochratoxin A Following Chronic Exposure to Rat and Subacute Exposure to Pig. Chem Res Toxicol. 17: 1289-1296.

Fazekas B, Tar A, Kovacs M. 2005. Ochratoxin A content of urine samples of healthy humans in Hungary. Acta Vet Hung. 53: 35-44. 
Fuchs R, Peraica M. 2005. Ochratoxin A in human kidney diseases. Food Addit Contam. Suppl 1: 53-57.

Geiser DM, Jimenez-Gasco M, Kang S, Makalowska I, Veerrarghavan N, Ward TJ, Zhang N, Kuldau GA, O’Donnell K. 2004. Fusarium-ID v. 1.0: A DNA sequence database for identifying Fusarium. Eur J Plant Pathol. 110: 473-479.

Gelderblom WCA, Marasas WFO, Farber E. 1992. The cancer initiating potential of the fumonisin B mycotoxins. Carcinogenesis. 13: 433-437.

Hanna GD, Phillips TD, Kubena LF, Cysewski SJ, Ivie GW, Heidelbaugh ND, Witzel DA, Hayes AW. 1981. High pressure liquid chromatographic determination of penicillic acid in chicken tissues. Poultry Sci. 60 (10): 2246-2252.

Hinojo MJ, Medina A, Valle-Algarra FM, Gimeno-Adelantado JV, Jimenez M, Mateo R. 2006. Fumonisin production in rice cultures of Fusarium verticillioides under different incubation conditions using an optimized analytical method. Food Microbiol. 23: 119127.

Howard PC, Warbritton A, Voss KA, Lorenzen RJ, Thurman JD, Kovach RM, Bucci TJ. 2001. Compensatory regeneration as a mechanism for renal tubule carcinogenesis of fumonisin B1 in F344/N/Nctr BR rat. Environ Health Persp. 109: 309-314.

Jurjevic Z, Solfrizzo M, Cvjetkovic B, Avantaggiato G, A, Visconti A. 1999. Ochratoxin A and fumonisins $\left(B_{1}\right.$ and $\left.B_{2}\right)$ in maize from Balkan nephropathy endemic and non endemic areas of Croatia. Mycotoxin Research. 15: 67-80.

Jurjevic L, Solfrizzo M, Cvjetkovic B, De Girolamo A, Visconti A. 2002. Occurrence of beauvericin in corn from Croatia. Food Technol Biotechnol. 40: 91-94.

Kanisawa M. 1984. Synergistic effect of citrinin on hepatorenal carcinogenesis of ochratoxin A in mice. Dev Food Sci. 7: 245-254.

Klaric MS, Rumora L, Ljubanovic D, Pepeljnjak S. 2007. Cytotoxicity and apoptosis induced by fumonisin B1, beauvericin and ochratoxin A in porcine kidney PK15 cells: effects of individual and combined treatment. Arch Toxicol. doi: 10.1007/s00204-007-0245-y.

Klich MA, Pitt JI. 1988. A Laboratory Guide to Common Aspergillus Species and Their Teleomorphs. North Ryde NSW: CSIRO Division of Food Research. pp 1-107.

Klich MA. 2002. Introduction; economic and medical importance of Aspergillus. In: Identification of common Aspergillus species. Centraalbureau voor Schimmelculture. Utrecht: The Netherlands (Publishers). pp. 1-16.

Kokkonen M, Jestoi M, Rizzo A. 2005. The effect of substrate on mycotoxin production of selected Penicillium strains. Int J Food Microbiol. 99: 207-214. 
Koshinsky HA, Khachatourians GG. 1994. Mycotoxicoses: The effects of mycotoxin combinations. In: Hui YH, Gorham JR, Murrell KD, Cliver DO. (Eds) Foodborne Disease Handbook. Diseases Caused by Viruses, Parasites, and Fungi. Vol. 2. Canada: University of Saskatchewan. Saskatoon. 463-520.

Krogh P, Axelsen NH, Elling F, Gyrd-Hansen N, Hald B, Hyldgaard-Jensen J, Larsen AE, Madsen A, Mortensen HP, Moller T, Peterson OK, Ravnskov U, Rostgaard M, Aalund O. 1974. Experimental porcine nephropathy: Changes of renal function and structure induced by ochratoxin A-contaminated feed. Acta Pathol Microb Scand Sect A. Suppl 246: 1-21.

Krogh P. 1976. Mycotoxic nephropathy. In: Advances in Veterinary Science and Comparative Medicine. vol. 20: Academic Press New York. 147-170.

Kubena LF, Edrington TS, Harvey RB, Phillips TD, Sarr AB, Rottinghaus GE. 1997. Individual and combined effects of fumonisin B1 present in fusarium moniliforme culture material and diacetoxyscirpenol or ochratoxin A in turkey poults. Poultry Sci. 76: 256264.

Kyriakidis N, Waight ES, Day JB, Mantle PG. 1981. Novel metabolites from Penicillium crustosum, including Penitrem E, a tremorgenic Mycotoxin. Appl Environ Microbiol. 42: (1) 61-62.

Le Bars J. 1980. Facteurs favorisant la production d'acide penicillique par le Penicillium verrucosum var. cyclopium dans les denrees alimentaires. Ann Rech Vet. 11: 321-326.

Lieu FY, Bullerman LB. 1977. Production and stability of aflatoxins, penicillic acid and patulin in several substrates. J. Food Sci. 42: 1222-1224.

Lieu FY, Bullerman LB. 1978. Binding of patulin and penicillic acid to glutathione and cysteine and toxicity of the resulting adducts. Milchwissensch. 33: 16-20.

Lillehoj EB, Ciegler A. 1975. Mycotoxin synergism. In: D. Schlessinger (Ed) Microbiology, American Society of Microbiology. Washington. DC. pp. 344-358.

Macgeorge KM, Mantle PG. 1990. Nephrotoxicity of Penicillium aurantiogriseum and P. commune from an endemic nephropathy areas of Yugoslavia. Mycopathologia. 112: 139145.

Manning RO, Wyatt D. 1984. Toxicity of Aspergillus ochraceus contaminated wheat and different chemical forms of ochratoxin A in broiler chicks. Poultry Sci. 63 (3): 458 - 465.

Mantle PG, McHugh KM. 1993. Nephrotoxic fungi in foods from nephropathy households in Bulgaria. Mycological Res. 97: 205 - 212.

Mantle P, Miljkovic A, Udupa V, Dobrota M. 1998. Does apoptosis cause renal atrophy in Balkan endemic nephropathy. The Lancet 352 (No9134): 1118-1119. 
Micco C, Miraglia M, Onori R, Libanori A, Brera C, Mantovani A, Macri C. 1991. Effect of combined exposure to ochratoxin A and penicillic acid on residues and toxicity in broilers. La Ravista della Societa Italiana di Scienza dell'Allimentazione. 20: 101-108.

Miljkovic A, Pfohl-Leszkowicz A, Dobrota M, Mantle PG. 2003. Comparative responses to mode of oral administration and dose of ochratoxin A or nephrotoxic extract of Penicillium polonicum in rats. Exp Toxicol Pathol. 54: 305-312.

Nelson PE, Toussoum TA, Marassas WFO. 1983. Fusarium Species: An illustrated manual for identification: The Pensylvania State Park. Pensylvanya. pp. 193.

Njobeh PB, Dutton MF, Chuturgoon AA, Koch SH, Steenkamp PA, Stoev SD. 2009. Identification of novel metabolite and its cytotoxic effect on human lymphocyte cells in comparison to other mycotoxins. Int J Biol Chem Sci. (in press).

Northolt MD, van Egmond HP, Paulsch WE. 1979. Ochratoxin A production by some fungal species in relation to water activity and temperature. J Food Protect. 42: 485-490.

Obrecht-Pflumio S, Dirheimer G. 2000. In vitro DNA and dGMP adducts formation caused by ochratoxin A. Chem. Biol Interact. 127: 29-44.

Obrecht-Pflumio S, Dirheimer G. 2001. Horseradish peroxidase mediates DNA and deoxyguanosine 3'-monophosphate adduct formation in the presence of ochratoxin A Arch Toxicol. 75: 583-590.

Oswald IP, Desautels C, Laffitte J, Fournout S, Peres SY, Odin M, Le Bars P, Le Bars J, Fairbrother JM. 2003. Mycotoxin fumonisin B-1 increases intestinal colonization by pathogenic Escherichia coli in pigs, Appl Environ Microbiol. 69 (10): 5870-5874.

Oswald IP, Bouhet S, Marin DE, Pinton P, Taranu I. 2005. Mycotoxin effects on the pig immune system. Proceedings of the European mycotoxin seminar series "Evaluating the Impact of Mycotoxins in Europe": European Lecture Tour, 22 February 2005, Sofia. pp 78-93.

Palmgren MS, Ciegler A. 1983. Toxicity and carcinogenicity of fungal lactones: patulin and penicillic acid. In: Keeler R.F. and Tu A.T (Eds) Handbook of natural toxins. Vol. 1. Plant and fungal toxins. New York. USA: Marcel Dekker Inc. pp 325-341.

Parker R, Phillips T, Kubena L. Russell LH, Heidelbaugh ND. 1982. Inhibition of pancreatic carboxypeptidase A: a possible mechanism of interaction between penicillic acid and ochratoxin A. J Environ Sci Hlth B17: 77-91.

Patterson DSP, Roberts BA. 1979. Mycotoxins in animal feedstuffs: Sensitive thin layer chromatographic detection of aflatoxin, ochratoxin A, sterigmatocystin, zearalenone and T2 toxin. J Assoc Off Anal Chem. 62: 1265-1267. 
Petkova-Bocharova T, Castegnaro M. 1991. Ochratoxin A in human blood in relation to Balkan endemic nephropathy and urinary tract tumours in Bulgaria. In: Mycotoxins, Endemic Nephropathy and Urinary Tract Tumours (Ed: M. Castegnaro, R. Plestina, G. Dirheimer, I. N. Chernozemsky, B. Bartsch). IARC. Lyon. pp. 135-137.

Petkova-Bocharova T, Castegnaro M, Michelon J, Maru V. 1991. Ochratoxin A and other mycotoxins in cereals from an area of Balkan endemic nephropathy and urinary tract tumours in Balgaria. In: Mycotoxins, Endemic Nephropathy and Urinary Tract Tumours (Ed: M. Castegnaro, R. Plestina, G. Dirheimer, I. N. Chernozemsky, B. Bartsch). Lyon. IARC. pp $83-87$.

Petrik J, Zanic'-Grubišic T, Barišic K, Pepeljnjak S, Radic B, Fereničic Z, Cepelak I. 2003. Apoptosis and oxidative stress induced by ochratoxin A in rat kidney. Arch Toxicol. 77: 685-693.

Pfohl-Leszkowicz A, Grosse Y, Castegnaro M, Nicolov IG, Chernozemsky IN, Bartsch H, Betbeder AM, Creppy EE and Dirheimer G. 1993. Ochratoxin A related DNA adducts in urinary tract tumours of Bulgarian subjects. IARC Scientific Public 124. pp 141-148.

Pfohl-Leszkowicz, Manderville R. 2007. Review on Ochratoxin A: an overview on toxicity and carcinogenicity in animals and humans. Mol Nutr Food Res. 51: 61-99.

Pfohl-Leszkowicz A, Tozlovanu M, Manderville R, Peraica M, Castegnaro M, Stefanovic V. 2007. New molecular and field evidences for the implication of mycotoxins but not aristolochic acid in Human Nephropathy and Urinary tract tumor. Mol Nutr Food Res. 51: 1131-1146.

Pfohl-Leszkowicz A, Molinié A, Tozlovanu M, Manderville RA. 2008. Combined toxic effects of ochratoxin A and citrinin, in vitro and in vivo. In: Food contaminants, mycotoxins and food allergen, DP Siantar, MW Trucksess, PM Scott \& EM Herman (eds), ACS Symposium series 1001, pp 56-80.

Pitt JI, Hocking AD. 1997. Primary keys and miscellaneous fungi. In: Fungi and Food Spoilage. $2^{\text {nd }}$ Edition. Blackie Academic and Professional. London, Weinheim, New York, Tokyo, Melbourne, Madras. pp 59-171.

Rahimtula AD, Bereziat JC, Bussachini-Griot V, Bartsch H. 1988. Lipid peroxidation as possible cause of Ochratoxin A toxicity. Biochem. Pharmacol. 37: 4469-4477.

Rubiales MV, Bragulat MR, Cabanes FJ. 1998. Mycotoxin production by Penicillium species in liquid medium. Revue Med. Vet. 149 (6): 526.

Samson RA, Seifert KA, Kuijpers AFA, Houbraken JAP, Frisvad JC. 2004. Phylogentic analysis of Penicillium Subgenus Penicillium using partial $\beta$-tubulin sequences. Studies in Mycology. 49: 175-200. 
Sansing GA, Lillehof EB, Detroy RW, Muller MA. 1976. Synergistic toxic effects of citrinin, ochratoxin A and penicillic acid in mice. Toxicon. 14: 213-220.

Shepherd EC, Philips TD, Joiner GN, Kubena LF, Heidelbaugh ND. 1981. Ochratoxin A and penicillic acid interaction in mice. J Environ Sci Health. B16: 557-573.

Singh K, Frisvad JC, Thrane U, Mathur SB. 1991. An illustrated manual on identification of some seed-borne Aspergilli, Fusaria, Penicillia and their mycotoxins. Danish government. Institute of Seed Pathology for Developing Countries. Hellerup. pp 8-12.

Smedsgaard J. 1997. Terverticillate penicillia studied by direct electrospray mass spectrometric profiling of crude extracts. II. Database and identification. Biochem Syst Ecol 25: 65-71.

Smedsgaard J, Frisvad JC. 1996. Using direct electrospray mass spectrometry in taxonomy and secondary metabolite profiling of crude fungal extracts. J Microbiol Methods 25: 517.

Smedsgaard J, Nielsen J. 2005. Metabolite profiling of fungi and yeast: from phenotype to metabolome by MS and informatics. J Exp Botany 56: 273-286

Stoev SD, Petkova-Bocharova TK. 1994. A possible role of ochratoxin A in a disease causation in connection with Balkan endemic nephropathy: Proceedings of the 8th International Congress on Animal Hygiene. September 12-16. St. Paul. Minnesota. USA. po 61-64.

Stoev SD. 1998. The Role of Ochratoxin A as a Possible Cause of Balkan Endemic Nephropathy and its Risk Evaluation. Vet Hum Toxicol. 40 (6): 352-360.

Stoev SD, Hald B, Mantle P. 1998a. Porcine nephropathy in Bulgaria: a progressive syndrome of complex of uncertain (mycotoxin) etiology. Vet Rec. 142: 190-194.

Stoev SD, Stoeva J, Anguelov G, Hald B, Creppy EE, Radic B. 1998b. Haematological, biochemical and toxicological investigations in spontaneous cases with different frequency of porcine nephropathy in Bulgaria, J Vet Med Series A. 45: 229-236.

Stoev SD, Grozeva N, Hald B. 1998c. Ultrastructural and toxicological investigations in spontaneous cases of porcine nephropathy in Bulgaria. Vet Arhiv 68 (2): 39-49.

Stoev SD, Anguelov G, Pavlov D, Pirovski L. 1999. Some antidotes and paraclinical investigations in experimental intoxication with ochratoxin A and penicillic acid in chicks, Vet Arhiv. 69: 179-189.

Stoev SD. 2000. Ultrastructural and antidote investigations into the experimental intoxication of chickens with ochratoxin A and penicillic acid. Folia Vet. 44 (2): 85-90. 
Stoev SD, Anguelov G, Ivanov I, Pavlov D. 2000a. Influence of ochratoxin A and an extract of artichoke on the vaccinal immunity and health in broiler chicks. Exp Toxicol Pathol. 52: 43-55.

Stoev SD, Goundasheva D, Mirtcheva T, Mantle P. 2000b. Susceptibility to secondary bacterial infections in growing pigs as an early response in ochratoxicosis. Exp Toxicol Pathol. 52: 287-296.

Stoev, S.D., Vitanov, S., Anguelov, G., Petkova-Bocharova, T., Creppy, E.E., 2001. Experimental mycotoxic nephropathy in pigs provoked by a mouldy diet containing ochratoxin A and penicillic acid. Vet. Res. Commun. 25, 205-223.

Stoev SD, Daskalov H, Radic B, Domijan A, Peraica M. 2002a. Spontaneous mycotoxic nephropathy in Bulgarian chickens with unclarified mycotoxin aetiology. Vet Res. 33 (1): 83-94.

Stoev SD, Paskalev M, MacDonald S, Mantle, PG. 2002b. Experimental one year ochratoxin A toxicosis in pigs. Exp Toxicol Pathol. 53: 481-487.

Stoev SD, Djuvinov D, Mirtcheva T, Pavlov D, Mantle P. 2002c. Studies on some feed additives giving partial protection against ochratoxin A toxicity in chicks. Toxicol Lett. 135: 33-50.

Stoev SD, Stefanov M, Denev S, Radic B, Domijan A, Peraica M. 2004. Experimental mycotoxicosis in chickens induced by ochratoxin A and penicillic acid and intervention by natural plant extracts. Vet Res Commun. 28 (8): 727-746.

Stoev SD. 2008a. Mycotoxic nephropathies in farm animals - diagnostics, risk assessment and preventive measures. In: Oswald, I, Taranu I, Pandalai SG (Eds). Effect of Mycotoxins in Farm Animals. Chapter 8. Transworld Research Network 37/661 (2), Fort PO. Trivandrum-695 023, Kerala. India. pp. 155-195.

Stoev SD. 2008b. Complex Etiology, Prophylaxis and Hygiene Control in Mycotoxic Nephropathies in Farm Animals and Humans. Int J Mol Sci. 9: 578-605.

Stoev SD, Dutton MF, Nkosi B. 2009. Cytotoxic effect of mycotoxins Ochratoxin A, Citrinin, Penicillic acid, Fumonisin B1 and their combinations on human peripheral blood mononuclear cells as measured by MTT assay. The Open Toxinol J. 2: 1-8.

Suzuki S, Satoh T, Yamazaki M. 1977. The pharmacokinetics of ochratoxin A in rats. Jpn J Pharmacol. 27: 735-744.

Taranu I, Marin DE, Bouhet S, Oswald IP. 2008. Effect of fumonisin on the pig. In: Oswald, I, Taranu I, Pandalai SG (Eds). Mycotoxins in Farm Animals. Chapter 5. Transworld Research Network 37/661 (2), Fort PO. Trivandrum-695 023, Kerala. India. pp. 91-111. 
Umeda M, Yamamoto T, Saito M. 1972. DNA-strand breakage of HeLa cells induced by several mycotoxins. Jpn J Exp Med. 42: 527-539.

Voss KA, Riley RT, Norred WP, Bacon CW, Meredith FI, Howard PC. 2001. An overview of rodent toxicities: liver and kidney effects of fumonisins and Fusarium moniliforme. Environ Health Persp. 109: 259-266.

Vrabcheva T, Usleber E, Dietrich R, Martlbauer E. 2000. Co-occurrence of ochratoxin A and citrinin in cereals from Bulgarian villages with a history of Balkan endemic nephropathy $\mathbf{J}$ Agric Food Chem. 48 (6): 2483-2488.

Wilkes JG, Sutherland JB. 1998. Sample preparation and high-resolution separation of mycotoxins possessing carboxyl groups J Chromatogr B. 717: 135-156.

Yeulet SE, Mantle PG, Rudge MS, Greig JB. 1988. Nephrotoxiciy of Penicillium aurantiogriseum, a possible factor in the aetiology of Balkan Endemic Nephropathy. Mycopathologia. 102: 21-30.. 
1

2

3

4

5

6

7

8

9

10

11

12

13

14

15

16

17

18

19

20

21

22

23

24

25

26

27

28

29

30

31

32

33

34

35

36

37

38

39

40

41

42

43

44

45

46

47

48

49

50

51

52

53

54

55

56

57

58

59

60

\section{Figures caption:}

Fig. 1. Macroscopic appearance of kidneys with mycotoxic porcine nephropathy (MPN). Different degree of enlargement and mottled or enlarged and pale appearance of kidneys in pigs of 6-8 month-age, taken at slaughter time.

Fig. 2. Green fluorescence of the new secondary fungal metabolite produced by $P$. polonicum, which was seen in most of the feed extracts and was found to differ from all known mycotoxins by its fluorescence, $R_{F}$ values, UV spectrum and molecular mass. 
Table 1. Concentration of various mycotoxins in feed samples from pig/chick farms in Bulgaria having nephropathy problems (enlarged and mottled or pale appearance of kidneys) at slaughter time.

\begin{tabular}{lccc}
\hline \multicolumn{1}{c}{ Mycotoxin } & $\begin{array}{c}\text { Concentration in feed } \\
\mu \mathrm{g} / \mathrm{kg}(\mathrm{ppb})\end{array}$ & $\begin{array}{c}\text { Percentage of } \\
\text { positive samples }(\%)\end{array}$ & $\begin{array}{c}\text { Number of } \\
\text { examined samples }\end{array}$ \\
\hline ochratoxin A (OTA) & $188.8 \pm 27.3$ & Year 2006 & 25 \\
penicilic acid (PA) & $838.6 \pm 223.9$ & 100 & 25 \\
citrinin (CIT) & $54.7 \pm 27.5$ & 88 & 25 \\
fumonisin B1 (FB1) & $5564.1 \pm 584.4$ & 92 & 25 \\
deoxynivalenol (DON) & $72.7 \pm 18.8$ & 96 & 25 \\
penitrem A (PenA) & $1840.4 \pm 243.8$ & 60 & 25 \\
zearalenone (ZEA) & $133.2 \pm 15.5$ & 100 & 25 \\
\hline & & 96 & 25 \\
ochratoxin A (OTA) & $376.4 \pm 63.9$ & Year 2007 & 25 \\
penicilic acid (PA) & $904.9 \pm 86.5$ & 100 & 25 \\
citrinin (CIT) & $120.5 \pm 43.3$ & 92 & 25 \\
fumonisin B1 (FB1) & $3254.5 \pm 480.6$ & 96 & 25 \\
deoxynivalenol (DON) & $51.4 \pm 8.5$ & 92 & 25 \\
penitrem A (PenA) & $713.9 \pm 88.2$ & 100 & 25 \\
zearalenone (ZEA) & $108.2 \pm 9.9$ & 96 & \\
\hline
\end{tabular}

\pm SEM (Standard error of the mean) 
Table 2. Concentration of various mycotoxins in serum samples from pig farms in Bulgaria having nephropathy problems (enlarged and mottled or pale appearance of kidneys) at slaughter time.

\begin{tabular}{lccc}
\hline \multicolumn{1}{c}{ Mycotoxin } & $\begin{array}{c}\text { Concentration in serum } \\
\mu \mathrm{g} / \mathrm{l}\end{array}$ & $\begin{array}{c}\text { Number of } \\
\text { positive samples }\end{array}$ & $\begin{array}{c}\text { Number of } \\
\text { examined samples }\end{array}$ \\
\hline ochratoxin A (OTA) & $28.8 \pm 25.1$ & Year 2006 & 10 \\
penicilic acid (PA) & $23.3 \pm 22.1$ & 8 & 10 \\
citrinin (CIT) & $1.3 \pm 0.6$ & 8 & 10 \\
deoxynivalenol (DON) & $7.6 \pm 7.6$ & 7 & 10 \\
penitrem A (PenA) & $64.0 \pm 55.9$ & 1 & 10 \\
zearalenone (ZEA) & $0.24 \pm 0.12$ & 3 & 10 \\
\hline & & 5 & 10 \\
ochratoxin A (OTA) & $6.3 \pm 4.9$ & Year 2007 & 10 \\
penicilic acid (PA) & $22.9 \pm 12.8$ & 9 & 10 \\
citrinin (CIT) & $1.6 \pm 0.6$ & 9 & 10 \\
deoxynivalenol (DON) & 0 & 0 & 10 \\
penitrem A (PenA) & $45.6 \pm 40.3$ & 3 & 10 \\
zearalenone (ZEA) & $0.33 \pm 0.17$ & 5 & \\
\hline
\end{tabular}

\pm SEM (Standard error of the mean) 
Table 3. Concentration of various mycotoxins in urine samples from pig farms in Bulgaria having nephropathy problems (enlarged and mottled or pale appearance of kidneys) at slaughter time.

\begin{tabular}{|c|c|c|c|}
\hline Mycotoxin & $\begin{array}{c}\text { Concentration in urine } \\
\mu \mathrm{g} / \mathrm{l}\end{array}$ & $\begin{array}{c}\text { Number of } \\
\text { positive samples }(\%)\end{array}$ & $\begin{array}{c}\text { Number of } \\
\text { examined samples }\end{array}$ \\
\hline \multicolumn{4}{|c|}{ Year 2006} \\
\hline ochratoxin A (OTA) & $3.5 \pm 1.1$ & 10 & 10 \\
\hline penicilic acid (PA) & $1.6 \pm 0.5$ & 6 & 10 \\
\hline citrinin $(\mathrm{CIT})$ & $1.7 \pm 0.4$ & 10 & 10 \\
\hline deoxynivalenol (DON) & $5.1 \pm 5.1$ & 1 & 10 \\
\hline penitrem A (PenA) & 0 & 0 & 10 \\
\hline zearalenone (ZEA) & $9.4 \pm 3.9$ & 10 & 10 \\
\hline \multicolumn{4}{|c|}{ Year 2007} \\
\hline ochratoxin A (OTA) & $6.2 \pm 2.3$ & 10 & 10 \\
\hline penicilic acid (PA) & $1.7 \pm 0.6$ & 6 & 10 \\
\hline citrinin $(\mathrm{CIT})$ & $1.8 \pm 0.4$ & 10 & 10 \\
\hline deoxynivalenol (DON) & 0 & 0 & 10 \\
\hline penitrem A (PenA) & 0 & 0 & 10 \\
\hline zearalenone (ZEA) & $13.1 \pm 5.6$ & 10 & 10 \\
\hline
\end{tabular}

\pm SEM (Standard error of the mean) 
Table 4a. Percentage of contaminated feed samples (25 samples for 2006 and 25 samples for 2007) with Fusarium, Penicillium and Aspergillus fungi, level of fungal contamination, number of strains isolated and number of toxinogenic strains isolated as well as kind of mycotoxins produced by each fungal strain in various feed samples from pig/chick farms in Bulgaria having nephropathy problems (enlarged and mottled or pale appearance of kidneys) at slaughter time.

\begin{tabular}{cccccc}
\hline $\begin{array}{c}\text { Strain } \\
\text { isolated }\end{array}$ & $\begin{array}{c}\text { Percentage of } \\
\text { contaminated } \\
\text { samples }(\%)\end{array}$ & $\begin{array}{c}\text { Range of fungal } \\
\text { contamination } \\
(\mathrm{cpu} / \mathrm{g})\end{array}$ & $\begin{array}{c}\text { Number of } \\
\text { strains } \\
\text { isolated }\end{array}$ & $\begin{array}{c}\text { Number of } \\
\text { toxinogenic } \\
\text { strains }\end{array}$ & $\begin{array}{c}\text { Kind of mycotoxins } \\
\text { produced } \\
\text { (number of species) }\end{array}$ \\
\hline
\end{tabular}

\section{Fusarium species}

Gibberella fujikuroi

(var. moniliformis)

$F$. verticillioides

(F. moniliforme)

F. oxysporum

F. graminearum

Penicillium species

$P$. viridicatum

(P. verrucosum)

P. commune

P. citrinum

P. expansum

P. aurantiogriseum

P. polonicum

P. solitum

P. freii

P. thomi

P. chrysogenum

P. crustosum

P. simplicissimum

$P$. purpurogenum

$P$. islandicum

P. allii

Aspergillus species

A. ochraceus

A. niger

A. wentii

A. candidus

A. fumigatus

A. flavus

A. oryzae

A. clavatus

A. restrictus

Eurotium amstelodami
80

8

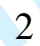

10

16

16

4

20

92

4

8

4

32

16

4

4

8

4

8

28

4

20

52

64

4

4

4

12
$3 \times 10^{3}-8 \times 10^{6}$

$3 \times 10^{3}-5 \times 10^{6}$

$2 \times 10^{3}-4 \times 10^{4}$

$2 \times 10^{3}-5 \times 10^{5}$

$4 \times 10^{3}-6 \times 10^{5}$

$3 \times 10^{3}-6 \times 10^{6}$

$4 \times 10^{3}-5 \times 10^{5}$

$2 \times 10^{3}-3 \times 10^{5}$

$5 \times 10^{3}-6 \times 10^{6}$

$4 \times 10^{3}-7 \times 10^{6}$

$2 \times 10^{3}-6 \times 10^{5}$

$5 \times 10^{3}-2 \times 10^{6}$

$4 \times 10^{3}-7 \times 10^{5}$

$2 \times 10^{3}-8 \times 10^{6}$

$2 \times 10^{3}-4 \times 10^{5}$

$2 \times 10^{3}-6 \times 10^{4}$

$4 \times 10^{3}-6 \times 10^{4}$

$3 \times 10^{3}-7 \times 10^{4}$

$2 \times 10^{3}-4 \times 10^{5}$

$4 \times 10^{3}-6 \times 10^{5}$

$3 \times 10^{3}-7 \times 10^{6}$

$2 \times 10^{3}-3 \times 10^{5}$

$4 \times 10^{3}-8 \times 10^{5}$

$3 \times 10^{3}-7 \times 10^{6}$

$4 \times 10^{3}-6 \times 10^{6}$

$2 \times 10^{3}-3 \times 10^{5}$

$3 \times 10^{3}-4 \times 10^{5}$

$4 \times 10^{3}-5 \times 10^{5}$

$3 \times 10^{3}-4 \times 10^{5}$
4

32

40

4

1

5

4

2

8

2

10

46

2

3

2

10

8

1

2

4

1

4

6

2

10

26

32

2

2

2

6
FB1(40), FB2(12), ZEA(10), MON(16), UM(4)

FB1(4), FB2(2),

ZEA(1), MON(1) ZEA(1)

ZEA(5), DON(5), T-2 (2), DAS(3), MON(1)

OTA(3), CIT(1), PA(4) $\mathrm{XA}(3), \mathrm{UM}(3)$

OTA(2), UM (2)

CIT(7), KA(4), UM(3)

CIT(1), PAT(1), UM(2)

$\mathrm{PA}(8), \mathrm{UM}(4)$

PA (42), UM (46)

$\mathrm{PA}(2), \mathrm{UM}(2)$

$\mathrm{PA}(3), \mathrm{UM}(3)$

$\mathrm{PA}(2), \mathrm{UM}(2)$

$\mathrm{PA}(8), \mathrm{UM}(10)$

PA(4), PenA(6), UM(5)

$\mathrm{PA}(1)$

RUB(1), KA(1), UM(1)

ERY(1), LUT(1), ISL(1), UM(2)

$\mathrm{UM}(1)$

OTA(2), PA(2), XA(1)

OTA(6), OTC(2)

OTA(1), KA(1)

CIT(1), KA(2), UM(10)

OTA(4), GLI(2),

$\mathrm{KA}(2), \mathrm{UM}(18)$

Afs (21), CA (12),

$\mathrm{KA}(14), \mathrm{UM}(24)$

$\mathrm{CA}(1), \mathrm{KA}(1)$

KA(1), PAT(1), UM(1)

$\mathrm{UM}(1)$

$\mathrm{UM}(1)$ 
Table 4b. Percentage of contaminated feed samples (25 samples for 2006 and 25 samples for 2007) with various other fungi, level of fungal contamination, number of strains isolated and number of toxinogenic strains isolated as well as kind of mycotoxins produced by each fungal strain in various feed samples from pig/chick farms in Bulgaria having nephropathy problems (enlarged and mottled or pale appearance of kidneys) at slaughter time.

\begin{tabular}{lccccc}
\hline \multicolumn{1}{c}{$\begin{array}{c}\text { Strain } \\
\text { isolated }\end{array}$} & $\begin{array}{c}\text { Percentage of } \\
\text { contaminated } \\
\text { samples }(\%)\end{array}$ & $\begin{array}{c}\text { Range of fungal } \\
\text { contamination } \\
(\mathrm{cpu} / \mathrm{g})\end{array}$ & $\begin{array}{c}\text { Number of } \\
\text { strains } \\
\text { isolated }\end{array}$ & $\begin{array}{c}\text { Number of } \\
\text { toxinogenic } \\
\text { strains }\end{array}$ & $\begin{array}{c}\text { Kind of mycotoxins } \\
\text { produced } \\
\text { (number of species) }\end{array}$ \\
\hline Acremonium strictum & 16 & $4 \times 10^{3}-5 \times 10^{5}$ & 8 & 2 & OOS(2) \\
Pichia guilliermondii & 4 & $3 \times 10^{3}-5 \times 10^{5}$ & 2 & - & - \\
Pichia caribbica & 28 & $4 \times 10^{3}-6 \times 10^{4}$ & 14 & - & - \\
Pichia fermentans & 4 & $3 \times 10^{3}-2 \times 10^{5}$ & 2 & - & - \\
Paecilomyces variotii & 12 & $2 \times 10^{3}-6 \times 10^{5}$ & 6 & - & - \\
Paecilomyces lilacinus & 4 & $2 \times 10^{3}-7 \times 10^{4}$ & 2 & - & - \\
Paecilomyces sinensis & 4 & $5 \times 10^{3}-6 \times 10^{5}$ & 2 & 1 & $\mathrm{UM}(1)$ \\
Absidia corymbifera & 4 & $2 \times 10^{3}-8 \times 10^{4}$ & 2 & - & - \\
Cladosp. cladosporioides & 8 & $4 \times 10^{3}-6 \times 10^{4}$ & 4 & - & - \\
Issatchenkia orientalis & 4 & $3 \times 10^{3}-3 \times 10^{5}$ & 2 & - & - \\
Talaromyces emersonii & 4 & $2 \times 10^{3}-3 \times 10^{5}$ & 2 & - & - \\
Cordiceps bassiana & 4 & $2 \times 10^{3}-2 \times 10^{5}$ & 2 & - & $\mathrm{UM}(1)$ \\
Mucor racemosus & 4 & $4 \times 10^{3}-6 \times 10^{5}$ & 2 & 1 & $\mathrm{UM}(3)$ \\
Mucor circinelloides & 16 & $4 \times 10^{3}-7 \times 10^{5}$ & 8 & 3 & - \\
Candida albicans & 4 & $2 \times 10^{3}-4 \times 10^{4}$ & 2 & - & - \\
Candida tropicalis & 8 & $3 \times 10^{3}-2 \times 10^{5}$ & 4 & - & $\mathrm{UM}(1)$ \\
Geomithia pallida & 4 & $2 \times 10^{3}-2 \times 10^{5}$ & 2 & 1 & - \\
Sacharomyces cerevisiae & 4 & $3 \times 10^{3}-6 \times 10^{4}$ & 2 & - & - \\
Galatomyces geotrichum & 4 & $2 \times 10^{3}-4 \times 10^{4}$ & 2 & - & - \\
Rhodotorula mucilaginosa & 4 & $4 \times 10^{3}-3 \times 10^{4}$ & 2 & - & \\
\hline
\end{tabular}


Fig. 1. Macroscopic appearance of kidneys with mycotoxic porcine nephropathy (MPN). Different degree of enlargement and mottled or enlarged and pale appearance of kidneys in pigs of 6-8 month-age, taken at slaughter time. $254 \times 190 \mathrm{~mm}(72 \times 72 \mathrm{DPI})$ 
Fig. 2. Green fluorescence of the new secondary fungal metabolite produced by $P$. polonicum, which was seen in most of the feed extracts and was found to differ from all known mycotoxins by its fluorescence, RF values, UV spectrum and molecular mass. $254 \times 190 \mathrm{~mm}(72 \times 72$ DPI $)$ 